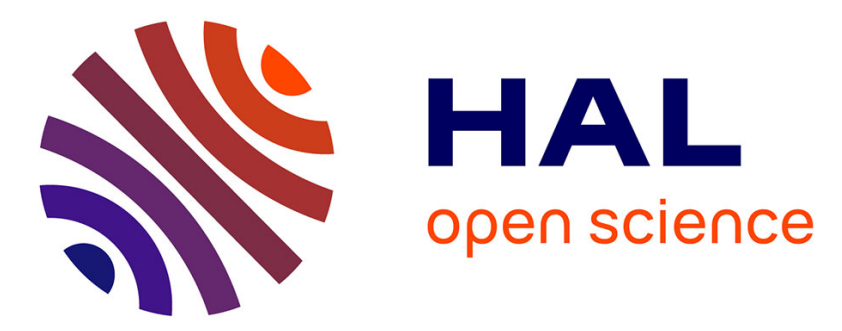

\title{
Modeling the coupling between free and forced convection in a vertical permeable slot: implications for the heat production of an Enhanced Geothermal System
}

Arnaud Battaillé, Pierre Genthon, Michel Rabinowicz, Bertrand Fritz

\section{- To cite this version:}

Arnaud Battaillé, Pierre Genthon, Michel Rabinowicz, Bertrand Fritz. Modeling the coupling between free and forced convection in a vertical permeable slot: implications for the heat production of an Enhanced Geothermal System. Geothermics, 2006, 35 (5-6), pp.654-682. 10.1016/j.geothermics.2006.11.008 . ird-00310440

\author{
HAL Id: ird-00310440 \\ https://hal.ird.fr/ird-00310440
}

Submitted on 8 Aug 2008

HAL is a multi-disciplinary open access archive for the deposit and dissemination of scientific research documents, whether they are published or not. The documents may come from teaching and research institutions in France or abroad, or from public or private research centers.
L'archive ouverte pluridisciplinaire $\mathbf{H A L}$, est destinée au dépôt et à la diffusion de documents scientifiques de niveau recherche, publiés ou non, émanant des établissements d'enseignement et de recherche français ou étrangers, des laboratoires publics ou privés. 


\title{
Modeling the coupling between free and forced convection in a vertical permeable slot: implications for the heat production of an Enhanced Geothermal System
}

\author{
Arnaud Bataillé $^{\mathrm{a}}$, Pierre Genthon ${ }^{\mathrm{a}, \uparrow}$, Michel Rabinowicz $^{\mathrm{a}, *}$, Bertrand Fritz $^{\mathrm{b}}$ \\ (a) Laboratoire de Dynamique Terrestre et Planétaire, UMR 5562, Observatoire \\ Midi-Pyrénées, 14 Avenue Edouard Belin, 31400 Toulouse, France \\ (b) Centre de Géochimie de Surface, UMR 7517, Ecole de l'Observatoire des \\ Sciences de la Terre, 1 rue Blessig, F-67084 Strasbourg, France \\ (†) Now at Hydrosciences/MSE, Univ. Montpellier II, France
}

Received 30 June 2004 ;

\begin{abstract}
The aim of the hydraulic stimulations in the Soultz-sous-Forêts, France, Enhanced Geothermal System (EGS) project was to create, in crystalline rocks, a fractured reservoir $750 \mathrm{~m}$ high, $750 \mathrm{~m}$ long and $35 \mathrm{~m}$ thick interconnecting the injection and production wells. Increasing the permeability in a zone with a high geothermal gradient will trigger free convection, which will interact with the forced flow driven by pumping. A systematic numerical study of the coupling between forced and free convective flows has been performed by considering a large range of injection rates and Rayleigh numbers. The simulations showed that if there is weak or no free convection in an EGS reservoir, economic exploitation of the system will rapidly end because of a decrease in produced fluid temperature. The maximum injection rate preventing such a temperature drop increases with the Rayleigh number and the height of the stimulated domain. The model establishes constraints on the conditions for achieving optimal heat extraction at the Soultz-sous-Forêts EGS site. It was also shown that although mineral precipitation may close or heal fractures, it does not lead to a major decrease of the hydraulic conductivity in the stimulated reservoir.
\end{abstract}


Keywords: Geothermal energy; Enhanced Geothermal Systems; EGS; Hot Dry Rock;

HDR; Free convection; Forced flow; Heat transfer; Soultz-sous-Forêts; France

* Corresponding author. Tel.: +33 56133 2962; fax: +33 561332900.

E-mail address: Michel.rabinowicz@cnes.fr (M. Rabinowicz) 


\section{Nomenclature}

$a \quad$ thickness of the fracture zone [m]

$\mathrm{a} / \mathrm{H}_{\mathrm{R}}$ dimensionless thickness of the fractured slot

$\mathrm{A} / 2$ half thickness of the modeled domain

$c_{P} \quad$ specific heat capacity $\left[\mathrm{J} /\left(\mathrm{kg}{ }^{\circ} \mathrm{C}\right)\right]$

$f \quad$ spacing of the fissure network [m]

$g$ gravitational acceleration $\left[\mathrm{m} / \mathrm{s}^{2}\right]$

$\mathrm{h} \quad$ height of layer at the bottom of the model [m]

$l \quad$ conduction length

$H \quad$ height of the fracture zone [m]

$k \quad$ permeability $\left[\mathrm{m}^{2}\right]$

L length of the fracture zone $[\mathrm{m}]$

$P \quad$ pressure $[\mathrm{Pa}]$

$P e_{g} \quad$ grid Peclet number

$P_{w} \quad$ thermal power $[\mathrm{MW}]$

$Q \quad$ injection rate $[\mathrm{L} / \mathrm{s}]$

$Q_{F} \quad$ free convection flow rate [L/s]

$\mathrm{R} \quad$ hydraulic conductivity [m]

$R a \quad$ Rayleigh number

$T \quad$ temperature $\left[{ }^{\circ} \mathrm{C}\right]$

$u$ horizontal velocity in the fractured slot $[\mathrm{m} / \mathrm{s}]$

$\mathrm{v}$ fluid velocity $[\mathrm{m} / \mathrm{s}]$

$\mathrm{v}_{\mathrm{D}} \quad$ Darcy fluid velocity $[\mathrm{m} / \mathrm{s}]$ 
w vertical velocity in the fractured slot $[\mathrm{m} / \mathrm{s}]$

Greek letters

$\alpha \quad$ coefficient of thermal expansion $\left[1 /{ }^{\circ} \mathrm{C}\right]$

$\Delta T \quad$ temperature difference between the top and bottom of the model $\left[{ }^{\circ} \mathrm{C}\right]$

$\delta \quad$ fissure aperture $[\mathrm{m}]$

$\varepsilon \quad$ porosity

$\theta \quad$ dimensionless temperature

$\kappa \quad$ thermal diffusivity $\left[\mathrm{m}^{2} / \mathrm{s}\right]$

$\lambda \quad$ thermal conductivity $\left[\mathrm{W} /\left(\mathrm{m}^{\circ} \mathrm{C}\right)\right]$

$\mu \quad$ fluid viscosity $[\mathrm{Pa} \cdot \mathrm{s}]$

$\rho \quad$ density $\left[\mathrm{kg} / \mathrm{m}^{3}\right]$

$\psi \quad$ stream function

Subscripts

C critical

f fluid

I initial

$\mathrm{N}$ normal to strike

$\mathrm{R} \quad$ reservoir (or stimulated zone)

$s \quad$ solid

S along strike

0 reference

* $\quad$ saturated porous media

dimensionless

\section{Introduction}


Since the 1970s, the increasing threat of a worldwide energy crisis has prompted many governments to try to reduce their dependence on traditional nonrenewable energy sources and to focus on renewable ones such as geothermal energy. Geothermal energy systems are most prevalent in regions of elevated heat flow and vigorous deep fluid circulation, such as The Geysers, USA, and Larderello, Italy. Aside from these hydrothermal systems, however, it is also possible to extract the heat stored in subsurface rock masses. In general, these rocks do not have an adequate natural permeability such as to guarantee the circulation of fluids needed to produce heat on a commercial scale, but this can be changed naturally by seismic events or artificially by hydraulic stimulation, both of which may create an extended region of permeable fractures. These man-made or artificially enhanced geothermal systems are called Hot Dry Rock (HDR) and/or Enhanced Geothermal Systems (EGS). The objective of EGS and HDR projects is to improve the productivity of naturally fractured systems and/or create new fractures to allow the circulation of large volumes of fluids through the hot rocks. In some instances EGS projects are targetted at increasing the output and commercial lifetime of an existing hydrothermal geothermal system. Since geothermal resources amenable to EGS- and HDR-type projects are widespread, they have stimulated considerable interest (Barbier, 2002). Several HDR projects have been launched in different parts of the world: e.g. at Fenton Hill (USA), in Cornwall (England), and Hijiori (Japan), and EGS projects are currently under way at Soultz-sous-Forêts (France), Coso (USA), Habanero (Australia).

Abé et al. (1999) stressed the importance of a thorough knowledge of the local geology and the mode of subsurface fluid circulation to the successful exploitation of EGS reservoirs. O'Sullivan et al. (2001) showed that it is essential we develop 
methods that predict the economic lifetime of a EGS, and particularly the fluid flow between production and injection wells, before proceeding with the full commercial implementation of an EGS project.

Several types of models have been developed, focusing on the thermal performance and flow characteristics of the regions with fluid circulation within the EGS. These models require a coupling of the thermal, mechanical, chemical and hydraulic processes occurring in the reservoir. Kohl et al. (1995) and Hicks et al. (1996) developed 2-D thermo-mechanical models that highlight the importance of thermo-elastic mechanisms on the behavior of EGS reservoirs over time. Kolditz and Clauser (1998) studied the forced circulation of a fluid in a fracture and the heat transfer between the fluid and surrounding rock using a 3-D finite-element model. A model based on a realistic stochastic fracture network accounts well for the observed early temperature drop in the fluid produced from EGS systems. Because the permeability of their model was small, free convection and, thus, fluid buoyancy were neglected.

Modeling of free convection in a fault was investigated by Murphy (1979) and Tournier et al. (2000). These authors represent the fault by a vertical porous slot with a high 2-D permeability field enclosed by impermeable but thermally conductive walls. They showed the effects of the heat exchange between the walls and the slot on the convective flow. The strength of the convection increases with the Rayleigh number:

$$
R a=\frac{\Delta \rho \cdot g \cdot H \cdot k}{\kappa \cdot \mu}
$$


where $\Delta \rho$ is the difference in fluid density between the top and bottom of the modeled domain, $\mu$ is the dynamic viscosity of the fluid, $g$ is gravity, and $\mathrm{k}, \mathrm{H}$ and $\kappa$ are the permeability, height, and thermal diffusivity of the porous slot, respectively. Based on a stability analysis, Murphy (1979) showed how the convective flow is dampened by the heat conducted through the lateral walls. He showed that convection starts instantaneously for a Rayleigh number $\mathrm{Ra}$, greatly exceeding the critical value for free convection in an infinite horizontal porous layer (i.e. $4 \pi^{2}$ ). He also showed that $\mathrm{Ra}_{\mathrm{I}}$ decreases with $a / H$, where $a$ is the thickness and $H$ the height of the permeable slot; in the cases considered in the present study, $\mathrm{Ra}_{\mathrm{I}}$ exceeds a few thousands. Murphy (1979) also defined a modified Rayleigh number $R a^{*}=\operatorname{Ra} \times(a / H)^{2}$ that determines the linear stability of the convection in a fault with different thickness-toheight aspect ratios. Rabinowicz et al. (1999) developed a model of convection in an equivalent porous permeable slot surrounded by conductive impermeable walls to simulate hydrothermal circulation at mid-ocean ridges. Using a similar numerical model, Tournier et al. (2000) reported a new critical Rayleigh number, Ra $a_{C}$, above which convection starts after a time delay. Considering the case of a highly permeable network in a fault system, Murphy et al. (1981) noted the simultaneous effects of free and forced convection within a fracture.

None of the modelling efforts described above evaluates the long-term profitability of an EGS system as a function of the Raleigh number of the stimulated volume located between the injection and production wells, the rate of fluid injection in the wells and of the dissolution/precipitation of minerals in the equivalent porous network during fluid circulation. Using data from the Soultz-sous-Forêts project, we have therefore developed a model specifically to study this profitability aspect. 
The Soultz-sous-Forêts site is located over a high heat flow anomaly in the extensional Upper Rhine Graben. The subsurface thermal gradients reflect a natural convective circulation at the scale of the entire Rhine basin, which includes the granite basement down to at least $5000 \mathrm{~m}$ and part of the sedimentary cover (Pribnow and Schellschmidt, 2000). This convection is slow and gives rise to temperature variations that can only be measured at geological time scales (Ormond et al., 1995). Hydraulic stimulation of the granitic volume around the drilled granitic section at the Soultzsous-Forêts site is expected to create a permeable region (or reservoir) connecting the wells, in which free convective circulation can develop.

The present study begins with a summary of the geological setting of the Soultz-sous-Forêts EGS project. We then present the appropriate equations for describing the numerical model developed to study the interaction of free convection with forced flow in a vertical slot simulating the fracture zone, including the stimulated reservoir connecting the injection and production wells (Fig. 1). Finally, we describe the results of modeling the long-term exploitation of this Enhanced Geothermal System both in terms of produced fluid temperature and mineral precipitation/dissolution in the fractures.

\section{Geological setting}

The European EGS project at Soultz-sous-Forêts started in 1987. Numerous well stimulation and circulation tests have been performed at various depths, providing the large database of reservoir parameters that is essential for numerical modeling of the site. Two boreholes, GPK1 and GPK2 were drilled and logged in 1993 and 1994; they reached 3590 and $3876 \mathrm{~m}$ depth, respectively. The external 
casings of the two boreholes are cemented from the wellhead to $1500 \mathrm{~m}$ depth; the internal casings are cemented below $2850 \mathrm{~m}$ and $3210 \mathrm{~m}$ depth, respectively. Both wells were drilled into the same fault segment and are $450 \mathrm{~m}$ apart. The open-hole portions of GPK1 and GPK2 have been hydraulically stimulated, thus enhancing the permeability of the natural reservoir connecting both wells (Baria et al., 1999). A third well, EPS1, drilled in 1987, is located close to GPK2. It is used as a test hole and has been fully cored from $930 \mathrm{~m}$ down to bottomhole. The large amount of data collected from EPS1 (including core samples, borehole images and hydraulic data) has provided constraints on the structural and mineralogical properties of the Soultz granite, and, hence, on the parameters used in our modeling study.

The Soultz granite hosts a high-salinity (100 g/L) brine (Pauwels et al., 1993). In the deep aquifers of the overlying sedimentary sequences, heat is transported by a convection system that is thermally coupled to a very slow, deep convective flow in the underlying granite that presents a set of natural sub-vertical N-S striking fractures. A knowledge of the geometry and the hydraulic characteristics of the fractured system is fundamental to our evaluation and exploitation of the EGS reservoir.

For Soultz, Genter et al. (1995) proposed, within the impermeable granite, a fault system consisting of a connected network of 10-m thick hydrothermally altered gouge zones some $100 \mathrm{~m}$ apart. The data collected from the deep wells reveal the presence of three zones associated with these fault gouges (Genter et al., 2002): (i) the fresh nonaltered granite forming the walls of the fault; (ii) the outer gouge consisting of hydrothermally altered granite, about $30 \%$ of which is clay-like material with a high porosity (10\%); and (iii) the central part of the gouge, $50 \%$ of which is represented by clay-like minerals, plus quartz and calcite, and a high density of fissures that are partially open and connected. 
Large-scale deformation in the Soultz granite due to the Rhine Graben tectonics mainly occurs through fault motion (Plenefisch and Bonjer, 1997). As a result, the set of gouges tends to run parallel to the direction of maximum shear stress, and eventually constitutes a connected network of more or less parallel, sub-vertical, 10-m thick sheets that have randomly distributed permeabilities. Outside these gouges, the granite is weakly altered and thus almost impermeable.

The effective permeability of the fault, that represents the equivalent Darcy permeability at the scale of the entire height of the fault itself, was estimated on the basis of numerous observations (e.g. core samples studies, borehole imagery, hydraulic tests). Estimates of the effective permeability of drill cores cut from the slightly altered granite range from about $10^{-20} \mathrm{~m}^{2}$ to $10^{-18} \mathrm{~m}^{2}$ (Genter and Traineau, 1993). On the other hand, the propagation of the microseismic cloud observed during the stimulation tests yielded estimated permeabilities for the slightly altered granite between $10^{-19} \mathrm{~m}^{2}$ and $10^{-17} \mathrm{~m}^{2}$ (Shapiro et al., 2002). This represents the range of permeability of the bulk rock outside the sub-parallel set of connected fault gouges.

Analysis of pressure test data collected prior to the stimulation experiments gave effective permeabilities in the $10^{-15}$ to $10^{-14} \mathrm{~m}^{2}$ range for the slightly altered granite (Hettcamp et al., 2002). Because of the low bulk permeability of this type of granite, the latter values result from the hydraulic interconnection of the open fissure network within the gouge systems. Downhole data show that the permeability of the naturally fractured granite in the 1400-4000 m depth interval essentially reflects the presence of the open 
fractures and of the highly porous altered granite found in the central and outer zones of the fault gouges.

The downhole temperature logs show that: (i) the mean geothermal gradient in the sediment cover, down to $1400 \mathrm{~m}$ depth, is about $100^{\circ} \mathrm{C} / \mathrm{km}$; (ii) the gradient drops by a factor of 3 between 1400 and $4000 \mathrm{~m}$ depth, to about $28^{\circ} \mathrm{C} / \mathrm{km}$; and (iii) the gradient increases again below $4 \mathrm{~km}$ depth. These data indicate that convective flow exists in the relatively homogeneous bottom part of the sediment cover and in the quasi-parallel and vertical set of gouges that occur at $1400 \mathrm{~m}$ depth and extend down to at least $4 \mathrm{~km}$. Inside the granitic rock mass, this convective flow is essentially confined to the fault gouges and, thus, is subparallel to the N-S strike of the gouges. As a first approximation, this fluid circulation can be envisaged as convective rolls whose axes are orthogonal to the gouge strike, similar to those observed in Hele-Shaw laboratory experiments (Hu and Steen, 1996).

The increase in geothermal gradient observed at depths greater than $4 \mathrm{~km}$ indicates that the lower convective boundary layer, and hence the bottom of the convection rolls, are close. The data indicate the existence of a convective process with flow lines parallel to the sub-vertical gouge system, and a Rayleigh number that exceeded several times the critical Rayleigh number (in this case, $\mathrm{Ra}_{\mathrm{C}}=4 \pi^{2}$ ) before the hydraulic stimulation of the granitic rocks.

Since all the parameters in Eq.(1), except permeability, are easy to estimate, we can deduce that the effective permeability of the fracture gouge network is $10^{-14} \mathrm{~m}^{2}$ or higher. This value falls within the range estimated by Pribnow and Schellschmidt (2000), i.e. $>10^{-14} \mathrm{~m}^{2}$. By analogy with 
comparable cases, we can deduce that the Darcy velocity of this convective flow is small, i.e. a few cm/yr (Rabinowicz et al., 1985). Because of the spacing of the gouges in the granitic mass (i.e. $10-\mathrm{m}$ thick sheets, $100 \mathrm{~m}$ apart), the gouge volume represents nearly $10 \%$ of the total volume. As a result, the Darcy velocity $v_{D}$ within the gouge is an order of magnitude greater than the bulk one. Thus, $\mathrm{v}_{\mathrm{D}}$ remains lower than a few $\mathrm{dm} / \mathrm{yr}$ : i.e. $\mathrm{v}_{\mathrm{D}}<1 \mathrm{~m} / \mathrm{yr}$.

The hydraulic pressure gradients created during stimulation re-open numerous fractures and separate blocks of granites that were welded together by mineral deposits precipitated during previous hydrothermal pulses. Hence, most of the fluid circulation in the stimulated reservoir occurs in open sets of pre-existing or newly developed flow channels or fractures. The distribution of the microseismic events recorded during the stimulation tests suggests that pressure waves were felt within a volume that can be considered as the EGS reservoir, whose length is about $750 \mathrm{~m}$ and width about $35 \mathrm{~m}$ (Pearson, 1981; Shapiro et al., 1999, 2002). Assuming that the flow is approximately one-dimensional, the bulk permeability of the stimulated reservoir connecting the two wells may be determined from the hydraulic parameters measured during the stimulations (Gérard et al., 1998):

$$
k_{E}=\frac{\mu \cdot v}{\nabla P_{i}}
$$

where $k_{E}$ is the effective permeability, $\mu$ the fluid viscosity, $v$ the fluid velocity calculated based on tracer test and $\nabla P_{i}$ the pressure gradient between the two wells. Using the injected flow rate, the injection pressure, and the estimated thickness of the stimulated reservoir, Eq. (2) yields an effective permeability of about $10^{-11} \mathrm{~m}^{2}$. Note that this value is two or three orders of 
magnitude greater than the estimated permeability of the fractured granite prior to hydraulic stimulation (about $10^{-14} \mathrm{~m}^{2}$ ).

According to the downhole temperature logs, the top of the vertical permeable slot is located just below the sedimentary cover, i.e. at about $1400 \mathrm{~m}$ depth, and its bottom lies below $4 \mathrm{~km}$. The propagation of the microseismic front ends along the boundary of the stimulated domain (Shapiro et al., 2002). As its width at the logging depth does not exceed $35 \mathrm{~m}$, it is plausible that the thickness of the permeable fractured slot, which hydraulically connects both wells from 1400 down to $4000 \mathrm{~m}$ depth, is also $35 \mathrm{~m}$ thick. Thus, we will assume that the hydraulically stimulated reservoir is approximately nested in the center of this slot, and has a height, length and thickness of about $750 \mathrm{~m}, 750 \mathrm{~m}$, and $35 \mathrm{~m}$, respectively (see Fig 1). However, the permeability of the stimulated reservoir and the fractured slot are likely to be heterogeneous, decreasing drastically as a function of distance to the main open fractures located near the central part of the gouge (zone iii; see above) and near one of the wells. As one or both of the wells was not drilled into this central part, the fluid circulating between the wells flows through a region of lower permeability (Zone ii). Accordingly, the $10^{-11} \mathrm{~m}^{2}$ effective permeability of the stimulated domain, calculated on the basis of hydraulic impedance during pumping, can be considered a minimum value.

\section{The numerical model}

\subsection{Physical model}


The well data suggest that the fractured slot can be modeled as a vertical permeable box about $35 \mathrm{~m}$ wide, $2250 \mathrm{~m}$ long and at least $2250 \mathrm{~m}$ high. This slot includes the $750 \mathrm{~m}$ high, $750 \mathrm{~m}$ wide and $35 \mathrm{~m}$ thick stimulated volume (Fig. 1). The two arrows shown in the figure indicate the injection and production points, separated by $450 \mathrm{~m}$ at a $3000-3875 \mathrm{~m}$ depth.

Since the fractures, which contribute most of the permeability to the slot, are nearly parallel to the direction of shear (i.e. to the plane of the fracture slot), the effective permeability in the direction perpendicular to shear $\left(k_{N}\right)$ is negligible. Thus, we assume $k_{N}=0$. The effective permeability of the slot inside the $750 \mathrm{~m} \times 750 \mathrm{~m} \times 35 \mathrm{~m}$ stimulated reservoir in the direction of strike $\left(k_{S}\right)$ is assumed to be $10^{-12} \mathrm{~m}^{2}$, a reasonable value when compared with the maximum value of $10^{-11} \mathrm{~m}^{2}$ estimated in the previous section. In the model the along-strike mean permeability $\left(k_{S}\right)$ for the region of the faulted slot outside of the stimulated reservoir is assumed to be more than two orders of magnitude lower (i.e. $10^{-14} \mathrm{~m}^{2}$ ), despite the fact that local high permeable features not directly connected to the wells could contribute to the drainage of the fractured slot.

The permeability parallel to the shear zone (i.e. $k_{S}$ ) and the porosity, $\varepsilon$, of the permeable fracture network can be considered to be a function of fissure aperture $\delta$ and spacing $f$; i.e.:

$$
\begin{aligned}
& k_{S}=\frac{\delta^{3}}{12 f} \\
& \varepsilon=\frac{\delta}{f} .
\end{aligned}
$$

In the stimulated reservoir, an aperture $\delta$ of about $0.23 \mathrm{~mm}$ and a spacing of about $1 \mathrm{~m}$ correspond to a porosity $\varepsilon$ of $2.3 \times 10^{-4}$ and a fracture 
permeability of $10^{-12} \mathrm{~m}^{2}$, the reference permeability in our model. Note that inside the fractured slot but outside the stimulated reservoir, a fracture aperture $\delta$ of about $0.05 \mathrm{~mm}$ and the same spacing $(\mathrm{f}=1 \mathrm{~m})$ could explain the along-strike permeability $k_{S} \approx 10^{-14} \mathrm{~m}^{2}$.

In the model, the fractured slot is parallel to the $\mathrm{XZ}$ plane containing the injection and the production points, with the Z-axis pointing vertically downwards and the X-axis horizontal (Fig. 1). The slot is bound between two conductive walls of infinite extent in the $\mathrm{Y}$ direction. Owing to the symmetry of the system, we consider only the half-space $y \geq 0$ : i.e., the half thickness of the fractured slot is $17.5 \mathrm{~m}$.

The numerical simulations are performed assuming two different permeability fields. In the first, the entire fractured slot has a uniform alongstrike permeability. In the other simulations, only the stimulated reservoir has the high permeability value, and four permeability ratios $\left(\mathrm{K}_{\mathrm{R}}\right)$ between the stimulated reservoir and the non-stimulated zone of the fractured slot are considered (i.e. $\mathrm{K}_{\mathrm{R}}=5,10,50$ and 100).

\subsection{Convection equations}

\subsubsection{Equation of flow}

In our numerical experiments (see Section 4), the Darcy velocity, $\mathrm{v}_{\mathrm{D}}$, attains, at most, $6.7 \times 10^{-5} \mathrm{~m} / \mathrm{s}$ : i.e. $\approx 2.1 \mathrm{~km} / \mathrm{yr}$. Comparing this last estimate with the Darcy velocity $v_{D}$ within the fractured slot, i.e. $v_{D}<1 \mathrm{~m} / \mathrm{yr}$, we conclude that the natural (pre-stimulation) fluid flow through the entire granitic layer is too slow to interact with the flow that develops inside the stimulated reservoir. Besides, the interstitial fluid velocity within the 
permeable fracture network inside the stimulated reservoir reaches a maximum value of $\mathrm{v}_{\mathrm{D}} / \varepsilon \approx 20 \mathrm{~cm} / \mathrm{s}$, which is low enough for the inertial terms to be negligible. Here we assume that these fractures are vertical even though the gouge planes are sub-vertical. Thus, a two-dimensional Darcy's flow describes fluid flow inside the fractured slot:

$$
\begin{aligned}
& u=-\frac{k_{S}}{\mu} \frac{\partial P}{\partial x} \\
& w=-\frac{k_{S}}{\mu}\left(\frac{\partial P}{\partial z}-\rho_{f} g\right)
\end{aligned}
$$

where $u$ and $w$ are the horizontal and the vertical velocity in the fractured slot, $P$ represents the fluid pressure, $\mu$ the fluid viscosity, $g$ the gravitational acceleration, and $\rho_{f}$ the fluid density. Here $u$ and $w$ depend on $\mathrm{x}, \mathrm{z}$, and also on $\mathrm{y}$, the coordinate perpendicular to the permeable slot as a consequence of density changes caused by temperature variations within the slot. It must be remembered that the plane $y=0$ coincides with the mid-plane of the fractured slot, and that the velocities $u$ and $w$ are zero when $\mathrm{y}>17.5 \mathrm{~m}$.

Since we do not consider compressibility effects in the model, the mass conservation equation can be written as:

$$
\frac{\partial\left(\rho_{f} u\right)}{\partial x}+\frac{\partial\left(\rho_{f} w\right)}{\partial z}=0
$$

This allows us to introduce the stream function $\psi$ for two-dimensional flow defined by: 
$u=\frac{1}{\rho_{f}} \frac{\partial \psi}{\partial z}$

$w=-\frac{1}{\rho_{f}} \frac{\partial \psi}{\partial x}$

The stream function represents the flow rate inside the flow tubes.

\subsubsection{Heat equation}

In order to determine the temperature field in the permeable slot, we must consider heat transfer between the fluid circulating in the fractures and the surrounding walls. In our models, the time step is defined as being equal to the minimum time required for the fluid to cross the vertical grid spacing $\mathrm{dz}$. With $\mathrm{dz}=17.6 \mathrm{~m}$ and $\mathrm{v}=6.7 \times 10^{-5} \mathrm{~m} / \mathrm{s}$, the time step is about 3 days. The corresponding conduction length is $l=4 \sqrt{\kappa \cdot t} \approx 2 \mathrm{~m}$, with thermal diffusivity $\kappa=10^{-6} \mathrm{~m}^{2} / \mathrm{s}$. The distance between two fractures (or fault gouges) is about 1 $\mathrm{m}$; i.e. each side of the rock walls heated by one fracture has a thickness $l \approx$ $0.5 \mathrm{~m}$. The time required to reach thermal equilibrium between the fluid and the rock is therefore less than the time step used in our model. As a result, we may assume that the temperature of the fluid and of the surrounding walls are equal and that the bulk thermal properties may be used to describe the saturated porous medium within the permeable slot. These properties are denoted by asterisks. The advection diffusion equation for the fractured slot (Eq. 10) and the heat conduction equation for the impermeable walls (Eq. 11) are: 
$\left(\rho \cdot c_{p}\right)^{*} \frac{\partial T}{\partial t}+\left(\rho \cdot c_{p}\right)_{f} \vec{v}_{D} \cdot \vec{\nabla} T=\lambda^{*} \nabla^{2} T$

$\left(\rho \cdot c_{p}\right)_{s} \frac{\partial T}{\partial t}=\lambda_{s} \nabla^{2} T$

(For consistency, in Eq. (10) "v" has been changed to " $v_{D}$ ")

where $\left(\rho \cdot c_{p}\right)$ and $\lambda$ are the volumetric heat capacity $\left[\mathrm{J} /\left(\mathrm{m}^{3 \circ} \mathrm{C}\right)\right]$ and the thermal conductivity $\left[\left(\mathrm{W} / \mathrm{m}^{\circ} \mathrm{C}^{-1}\right)\right]$, respectively; '*', ' $f$ ' and ' $s$ ' refer to the saturated porous medium, the fluid and the solid properties, respectively, and $\vec{v}_{D}$ is the Darcy's fluid velocity. Here the temperature $T$ depends on $\mathrm{x}, \mathrm{y}$, and $\mathrm{z}$, and $\vec{v}_{D}$ is included in the XY plane. We assume that the thermal diffusivity of the saturated porous rock in the fractured domain and that of the weakly alteredgranitic rock are the same, i.e. $\kappa=\lambda^{*} /\left(\rho \cdot c_{p}\right)^{*} \approx \lambda_{s} /\left(\rho \cdot c_{p}\right)_{s}$

\subsection{Scaling of the equations and numerical methods}

The numerical method used here consists of coupling a 2-D fluid flow code for the porous slot with a unique 3-D solver for the temperature field in the fractured slot and its walls. This is achieved by setting $\vec{v}=0$ in Eq. (10) outside the fractured slot $(y>17.5 \mathrm{~m})$. The temperature and the flow equations become dimensionless by using the following scaling factors: in the uniform permeability cases the length scale $H$ is the height of the convective domain (i.e. $2250 \mathrm{~m}$ plus $\mathrm{h}=200 \mathrm{~m}$ of impermeable granite bottom layer, see below), $H$ $=2450 \mathrm{~m}$, the time unit is $H^{2} / \kappa=6 \times 10^{12} \mathrm{~s}$, and the Darcy velocity unit is $\kappa / H$ $=4 \times 10^{-10} \mathrm{~m} / \mathrm{s}$, while in the non-uniform permeability cases, $H=2250 \mathrm{~m}$ and represents the total height of the convective domain only. Then, $H^{2} / \kappa$ and $\kappa / H$ 
are changed accordingly. The dimensionless time $\mathrm{t}^{\prime}=\kappa t / H^{2}$ and the dimensionless Darcy velocity is $v_{D}^{\prime}=H v / \kappa$. The permeability $k_{S}$ is scaled by the permeability assigned to the stimulated reservoir at the center of the fractured slot. The dimensionless injection rate $Q^{\prime}$ is related to the dimensional one $Q$ by $Q^{\prime}=Q^{\prime}(\kappa H)$. The dimensionless temperature is $\theta=(T$ $\left.T_{0}\right) / \Delta T$ where $\Delta T=60^{\circ} \mathrm{C}$ is the difference in temperature between the top and bottom of the model, and $T_{0}=140^{\circ} \mathrm{C}$ is the constant temperature at its top. These values are consistent with recorded logging temperatures.

The dependence of fluid density $\rho_{f}$ on temperature is given by:

$\rho_{f}(\theta)=\rho_{0}(1-\alpha \cdot \Delta T \cdot \theta)$

where $\rho_{0}=980 \mathrm{~kg} / \mathrm{m}^{3}$ is the fluid density at $T=140^{\circ} \mathrm{C}$ and at $P=490$ bars. The fluid thermal expansion coefficient $\mathrm{s} \alpha=10^{-3} /{ }^{\circ} \mathrm{C}$ at temperatures ranging from 80 to $200^{\circ} \mathrm{C}$ and at a pressure of about 600 bars (Jung et al., 1997).

Thus, in the fracture, the dimensionless heat equation becomes:

$\gamma \frac{\partial \theta}{\partial t^{\prime}}+\vec{v}_{D}^{\prime} \cdot \vec{\nabla} \theta=\nabla^{2} \theta$

where $\mathrm{t}^{\prime}$ and $\vec{v}_{\mathrm{D}}$ ' are the dimensionless time and velocity, respectively, and $\gamma$ $=\left(\rho c_{p}\right)^{*} /\left(\rho c_{p}\right)_{\mathrm{f}}$ is the ratio of the granite volumetric thermal capacity to that of the geothermal fluid.

Therefore, the dimensionless flow equation is given by:

$\frac{1}{\mathrm{r}} \times \nabla^{2} \psi^{\prime}=-\left(\frac{\partial}{\partial \mathrm{x}^{\prime}}\left(\frac{1}{\mathrm{r}}\right) \times \frac{\partial \psi^{\prime}}{\partial \mathrm{x}^{\prime}}+\frac{\partial}{\partial \mathrm{z}^{\prime}}\left(\frac{1}{\mathrm{r}}\right) \times \frac{\partial \psi^{\prime}}{\partial \mathrm{z}^{\prime}}\right)-\operatorname{Ra} \times \frac{\partial(\theta)}{\partial \mathrm{x}^{\prime}}$ 
where dimensionless variables for the distance and stream function are designated by primes. Here, the driving term of the motion $-\operatorname{Ra} \times \frac{\partial(\theta)}{\partial x^{\prime}}$ depends on $y^{\prime}$, the coordinate perpendicular to the fractured slot; this term generally has its maximum value at the axis of the stimulated reservoir. The factor $r=$ $\mathrm{R} / \mathrm{R}_{0}$ is the dimensionless hydraulic conductivity, which is a function of both temperature and distance. The dimensional hydraulic conductivities are: $\mathrm{R}=$ $k_{S} \cdot \rho_{f} \cdot g / \mu$ and $\mathrm{R}_{0}=k \cdot \rho_{0} \cdot g / \mu_{0}$, where $\mu_{0}$ is the reference viscosity. In practice, the difference in fluid viscosity between the top and the bottom of the porous slot is not large enough to alter the convective flow (Kestin et al., 1978):

$\Delta \mu=\mu_{T=140^{\circ} \mathrm{C}} / \mu_{T=200^{\circ} \mathrm{C}}=1.4$

Only the temperature contrast between the injected fluid $\left(T=80^{\circ} \mathrm{C}\right)$ and the initial reservoir temperature $\left(T=160^{\circ} \mathrm{C}\right)$ is likely to lead to a local viscosity contrast. However, if the fluid has been heated up quickly at the contact with the surrounding rock, the local viscosity variation cannot modify the flow at some distance from the injection well. After performing a sensitivity analysis, we verified that the circulation of the fluid is not sensitive to such viscosity variations. Thus, a constant fluid viscosity of $3 \times 10^{-4} \mathrm{~Pa} \cdot \mathrm{s}$ was used in the models. Consequently, the Rayleigh number that characterizes the strength of the convection is only a function of the height of the porous slot $H$, the density difference across the convective domain $\Delta \rho$, and the permeability $k_{S}$.

The calculations are performed in a simulation domain of dimensionless height widz $=1$, length widx $=1$, and width widy that is adjusted to represent $300 \mathrm{~m}$ in both the uniform and non-uniform permeability cases. We use a set 
of $(128 \times 64 \times 128)$ equidistant grid points corresponding to a mesh volume of $19.1 \mathrm{~m} \times 4.7 \mathrm{~m} \times 19.1 \mathrm{~m}$ for the uniform permeability case, and a $17.6 \mathrm{~m} \times$ $4.7 \mathrm{~m} \times 17.6 \mathrm{~m}$ mesh volume for the non-uniform permeability case. The regularity of the grid spacing is known to minimize numerical dispersion when solving the heat equation using finite differences techniques (Patankar, 1980). In that case, four vertical (x', z') planes are located inside half of the fractured slot. Such gridding permits a satisfactory modelling of the convective flow (Rabinowicz et al., 1999).

The three-dimensional heat equation is solved by means of the alternativedirection implicit finite difference method (Yanenko, 1968). Inside the fractured slot, the two-dimensional convective flow is solved by means of a spectral decomposition method. The numerical method used here is identical to that described by Rabinowicz et al. (1999).

\subsubsection{Free convection and forced circulation}

At each iteration, the free convection velocity field is combined with the forced velocity field induced by pumping, which is computed once for each permeability distribution using a routine based on the multi-grid method (Press et al., 1992). Due to the high fluid velocities near the injection and production wells, we used three different schemes to model the advection term in the heat equation (Eq. 13): (i) the finite centered difference scheme, (ii) the exponential scheme, and (iii) the upwind scheme (Patankar, 1980). The precision for each of these schemes depends on the value of the grid Peclet number $P_{g}=|u| \times \Delta x$, where $\Delta x$ is the grid spacing and $|u|$ the maximum flow velocity in the $\mathrm{x}$ direction. 
Near the injection point, the temperature field is solved using the upwind scheme, which ensures numerical stability but can result in large artificial dispersion when locating the thermal front. Thus, the injection zone is not a point source but an injection spot. Fitzgerald et al. (1996) established an experimental law giving the temperature profile in the wall as a function of the position with respect to the injection spot. We check that our computed temperature profiles are in good agreement from that predicted by these authors.

\subsubsection{Boundary and initial conditions}

We impose adiabatic conditions on the vertical sides of the domain and impermeable conditions on the four boundaries of the porous slot ( $\psi$ is zero along these boundaries). The dimensionless temperature $\theta$ along the top and bottom of the domain remains constant and is equal to 0 and 1 , respectively. The former conditions are consistent with the fact that: i) the $y^{\prime}=0$ plane is the plane of symmetry for the $2 \times 17.5=35-\mathrm{m}$ thick fractured slot, and ii) the plane $\mathrm{y}^{\prime}=$ widy $(\approx 300 \mathrm{~m})$ is too far from the fractured slot for the temperature field to be influenced by a convective process lasting about 20 years. In several uniform permeability experiments, the cooling front reaches the bottom interface of the permeable slot, there resulting in the development of a steep thermal boundary layer. To accurately model the heat transfer in this zone, we fix the conductive temperature of the model at $\mathrm{h}=200 \mathrm{~m}$ below the slot bottom (this explains why the slot plus the bottom impermeable granite basement for uniform permeability cases is at $H=2250 \mathrm{~m}+200 \mathrm{~m}=2450 \mathrm{~m}$ ). The cooling front reaches the base of the $200-\mathrm{m}$ thick conductive layer after a 
period of $t^{\prime}=5.25 \times 10^{-4}(\approx 100$ years $)$; i.e. far longer than the expected life of the planned EGS plant.

More generally, with the same configuration, but when there is no forced flow (i.e. no fluid is injected or produced), the time necessary to develop both the top and bottom boundary layers is large: it represents a fraction of the dimensionless time, i.e. much more than $\approx 10,000$ years. As a result, in the experiments with a forced cold flow, we did not observe the development of a top boundary layer. As no front developed there, we did not include a top conductive horizontal layer in the model.

The numerical simulations began with a 3-D conductive temperature field given by: $\Theta\left(x^{\prime}, y^{\prime}, z^{\prime}\right)=1-z^{\prime}$. In the free convection simulations, the convection was triggered by introducing a thermal perturbation of the conductive temperature field according to:

$\Theta\left(x^{\prime}, y^{\prime}, z^{\prime}\right)=1-z^{\prime}+0.1 \times \sin \left(\pi z^{\prime}\right) \times \operatorname{ran}\left(x^{\prime}, y^{\prime}\right)$

where $\operatorname{ran}\left(\mathrm{x}^{\prime}, \mathrm{y}^{\prime}\right)$ is a random function between 0 and 1 . The introduction of this "noise" considerably hastened the development of the non-linear convective regime, which in any case requires more than 10,000 years to be established, a time period that is far too long when compared with the expected life of the EGS plant.

\section{Results}

Since the geometry is fixed, the distribution of temperature in the reservoir will depend only on the Rayleigh number, the injection rate and the permeability field. The effects of these three parameters are discussed below. 


\subsection{Uniform permeability}

We consider dimensionless injection rates $Q^{\prime}$ varying between 1.78 and $44.4(4 \mathrm{~L} / \mathrm{s}$ and $100 \mathrm{~L} / \mathrm{s})$ and Rayleigh numbers of 4050, 8100 and 16,200, which correspond to a slot permeability of $k_{S}=10^{-12} \mathrm{~m}^{2}, 2 \times 10^{-12} \mathrm{~m}^{2}$ and $4 \times 10^{-12}$ $\mathrm{m}^{2}$, respectively. The period of simulation is $\mathrm{t}^{\prime}=1.07 \times 10^{-4}(\approx 20$ years $)$.

First we describe the thermal field at a fixed dimensionless injection rate of $17.8(40 \mathrm{~L} / \mathrm{s})$ for each Rayleigh number (Figs. 2 to 5). Other injection rates are then considered.

Since the injectate is colder than the in-situ fluid, a steep thermal front develops at the contact with the hotter water in the permeable slot. When buoyancy of the cold fluid is not considered in the model, i.e. when $\mathrm{Ra}=0$, the front develops radially and is gradually smoothed by diffusion (Figs. 2ad). After $\mathrm{t}^{\prime}=1.6 \times 10^{-5}(\approx 3$ years $)$, the front reaches the production point and a drastic drop in the temperature of the produced fluid is observed (Fig. 2f). If the Rayleigh number is 4050 (Fig. 3), similar results are obtained.

When using the highest Rayleigh number, $(\mathrm{Ra}=16,200)$, the cold (and denser) injectate flows downwards and spreads along the bottom of the slot (Figs. 5a-d). Along this lower interface a steep thermal boundary layer develops, as indicated by the compressed isotherms. Two diffuse rising currents develop on both sides of the cold-water tongue. One of them is captured by the flow toward the production point, slightly increasing the temperature of the produced fluid (Fig. 5f). As the cold tongue spreads outwards, it displaces plumes rising on each side of the fracture (Fig. 5e), resulting in a slight drop in the produced fluid temperature. When using $\mathrm{Ra}=8100$ (Fig. 4), the behavior of the system is intermediate between that observed for $\mathrm{Ra}=$ 4050 and $\mathrm{Ra}=16,200$. The cold front is advected downward while it spreads radially, 
reaching the production point after a long time lag. In all the simulations, the slot walls are cooled by the injected fluid over a distance $l$ equal to $4 \sqrt{\kappa \cdot t}$ (i.e. $100 \mathrm{~m}$ ) after $t^{\prime}=1.07 \times 10^{-4}(\approx 20$ years $)($ Figs. 2e, 3e, 4e, 5e $)$.

As a result, two types of behavior are observed, depending on the value of the Rayleigh number and the injection rate. For a low Ra and a $Q^{\prime}$ of 17.8 (40 $\mathrm{L} / \mathrm{s}$ ), the free convection is relatively slow and the cold front develops laterally, affecting the fluid production temperature after $\mathrm{t}^{\prime}=2.14 \times 10^{-5}(\approx 4$ years). For higher Ra, the variations of fluid density with temperature drive the flow. The injected fluid is dragged toward the bottom of the fracture by thermal convection. As a result, the production temperature does not change, even after $\mathrm{t}^{\prime}=1.07 \times 10^{-4}(\approx 20$ years $)$.

We can therefore define a critical dimensionless injection rate $Q_{\mathrm{C}}$ ' below which the production zone remains isolated from the cold injectate for $t^{\prime}$ $\leq 1.07 \times 10^{-4}$ ( $\approx 20$ years $)$, preventing a dramatic drop of the extracted fluid temperature. Conversely, at rates larger than $Q_{C}$ ', the production temperatures show significant decreases (Fig. 6).

In the following section, a given injection rate will be described as "subcritical" or "supercritical" when it is lower or higher than the critical injection rate, respectively. The critical injection rates $Q_{C}$ and dimensionless critical injection rates $Q_{C}$ ', for Ra varying between 2025 and 24,300, are given in Table 1. Figure 7 shows how the produced thermal power changes with time. Thermal power $P_{w}$ is given by:

$$
\mathrm{P}_{\mathrm{w}}=\left(\rho c_{p}\right)_{f} Q^{\prime} \kappa H \Delta T
$$

where $\left(\rho c_{p}\right)_{f}$ is the volumetric heat capacity of the fluid and $\Delta T$ the temperature difference between the produced and injected fluids. For $Q^{\prime}=17.8$ 
$(40 \mathrm{~L} / \mathrm{s})$ and $\mathrm{Ra}=4050,8100$ and 16,200 , at $\mathrm{t}^{\prime}=1.07 \times 10^{-4}(\approx 20$ years $)$, the thermal power of the produced fluids amounts to $13.1 \mathrm{MW}, 15.2 \mathrm{MW}$ and 15.6 MW, respectively (Fig. 7). Thus, increasing the slot permeability by a factor of four (i.e. raising $\mathrm{Ra}$ from 4050 to 16,200 ) improves the thermal yield of the slot by $20 \%$ (at t' $\approx 20$ years). These results show that the thermal power does not increase linearly with the slot permeability. In fact, an infinitely large Rayleigh number would result in an extraction temperature close to that at the bottom of the fractured slot, and a thermal power of $20 \mathrm{MW}$.

\subsection{Comparison between injection and free flow}

In the previous section, we emphasized that there is competition between free convection and the forced flow driven by pumping, which leads to a calculation of the characteristic flow rate for free convection, $Q_{\mathrm{F}}$ '. Murphy (1979) and Tournier et al. (2000) showed that free convection inside a vertical fracture begins gradually, because of the transient heat exchange between the convecting fluid and the surrounding rock. A quasi-steady convection state is, however, observed when the heat transfer between the fluid in the slot and the fracture walls reaches a constant asymptotic value. This steady convection pattern is used to assess the fluid flow rate $Q_{\mathrm{F}}$ ' transported in the fracture by free convection; $Q_{\mathrm{F}}$ ' is related to the stream function $\psi$ ', which represents the flow rate inside the flow tubes (see Eqs. 5-9). As a result, $Q_{\mathrm{F}}$ ' corresponds to the product of the maximum dimensionless stream function value $\left|\psi^{\prime}\right|_{\max }$ and the dimensionless slot aperture $a^{\prime}\left(a^{\prime}=a / H\right)$, i.e.:

$Q_{F}^{\prime}=\mathrm{a}^{\prime}\left|\psi^{\prime}\right|_{\max }$ 
It should be noted that, at the highest values of Ra, fluid flow is mainly confined along the outer parts of the convection cells, whereas at lower Ra it occurs both within the periphery of the cells and at their core.

The non-dimensional $Q_{\mathrm{F}}$ ' is calculated for Ra values in the 0-24,300 range. The maximum dimensionless free convection velocity varies between 472 (2.1 $\left.\times 10^{-7} \mathrm{~m} / \mathrm{s}\right)$ and $3825\left(1.7 \times 10^{-6} \mathrm{~m} / \mathrm{s}\right)$ when Ra increases from 2025 to 16,200 . Table 1 presents the dimensionless $\left(Q_{\mathrm{F}}{ }^{\prime}\right)$ and dimensional free convection $\left(Q_{\mathrm{F}}\right)$ rates for various Rayleigh numbers varying between 2025 and 24,300, showing that $Q_{\mathrm{F}}$ ' increases approximately linearly with $\mathrm{Ra}$, according to the formula:

$Q_{\mathrm{F}}{ }^{\prime}=3 \times 10^{-4} \times \mathrm{Ra}-0.4$

When $\mathrm{Ra}>16,200, Q_{\mathrm{F}}$ ' stops growing linearly with Ra. This Ra value is close to $\mathrm{Ra}_{\mathrm{I}}$, the Rayleigh number above which convection starts instantaneously (Tournier et al., 2000). This is due to the fact that heat transport is increased by the appearance of a growing number of convection cells without any notable increase in fluid flow velocities in the plumes. Therefore, the convective velocities and flow rate do not increase linearly with Ra. A similar situation can be achieved by increasing the thickness of the slot. Murphy (1979) showed that the strength of the convection increases with the square of the slot aperture. Accordingly, when the aperture or thickness (a) of the fractured slot being modeled is large, the convective flow quickly becomes chaotic. The simulations performed with smaller Ra have, however, 
shown that both $Q_{\mathrm{F}}$ ' and $Q_{\mathrm{C}}$ ' are linearly related to the thickness of the dimensionless fracture $a^{\prime}$.

\subsection{Non-uniform permeability}

In this section we consider a fractured slot whose permeability is much lower than that of the central stimulated domain (i.e. the core of the slot). The configuration may be adjusted by changing the ratio $K_{R}$ of the permeability of the stimulated core relative to that of the non-stimulated external zone. The Rayleigh number is computed using the permeability of the central zone and the total height of the domain $(H=2250 \mathrm{~m})$. We use four Ra values $(0,4050,8100$ and 16,200$)$ and a dimensionless injection rate of 17.8 $(40 \mathrm{~L} / \mathrm{s})$. As discussed in the previous section, this injection rate is higher than the $Q_{\mathrm{C}}$ ' for $\mathrm{Ra}=4050$, and lower than that for $\mathrm{Ra}=16,200$.

Figures 8 to 11 (a to d) illustrate the temperature field at $t^{\prime}=1.07 \times 10^{-4}$ (20 years) and Figs. 8 to 11 (e) the change in fluid production temperature with time. The permeability ratios $K_{R}$ are assumed to be equal to $1,5,10,50$ and 100. A decrease of $K_{R}$ is associated with an increase in production temperature. The propagation of the cold front through the system is similar to that observed in the uniform permeability case (i.e. $K_{R}=1$ ) until the injected fluid reaches the "permeability barrier" (i.e. the contact between the stimulated and non-stimulated zone). The effect of confining fluid convection mainly to the stimulated zone (i.e. the "confinement effect") is significant after about $\mathrm{t}^{\prime}=2 \times 10^{-5}$ (4 years) when $\mathrm{Ra}=4050$ and 8100 (Figs. 9e and 10e), and after $t^{\prime}=10^{-5}$ (2 years) when $\mathrm{Ra}=16,200$ (Fig. 11e). 
For $\mathrm{Ra}=0$ and 4050 , the colder injected fluid starts to propagate radially away from the injection well. When it reaches the permeability barrier, the cold front is deflected toward the production well. This effect of flow confinement becomes evident when the temperature of the produced fluid starts to drop (Figs. 8 and 9). For $\mathrm{Ra}=16,200$, the injected fluid immediately propagates downward towards the permeability barrier. The cold descending convective plume then splits into two upwelling plumes, one of which is confined below the production point. This results in a transient rise of the fluid production temperature (Fig. 11). Finally, the cold fluid is captured by the production well and the temperature of the produced fluid starts to decrease rapidly, an effect amplified by the confinement of the flow (i.e. high $\mathrm{K}_{\mathrm{R}}$ case). For $\mathrm{Ra}=8100$ (Fig. 10), the cold fluid first propagates radially and then slightly downwards. Soon after it reaches the permeability barrier, the temperature of the produced fluid decreases, as in the case of $\mathrm{Ra}=4050$ (Fig. 9).

In all simulations, the dimensionless injection rate of $17.8(40 \mathrm{~L} / \mathrm{s})$ is supercritical (See Section 4.1). To constrain the effect of flow confinement on heat production, we evaluate the dimensionless free convective flow rate $Q_{\mathrm{F}}$ ' and critical injection rate $Q_{\mathrm{C}}$ ' for cases in which the permeability ratio $\mathrm{K}_{\mathrm{R}}=$ 100 and the Rayleigh numbers range from 0 to 24,300 . The $Q_{\mathrm{F}}$ ' and $Q_{\mathrm{C}}{ }^{\prime}$ values used for the uniform $\left(K_{R}=1\right)$ and non-uniform permeability $\left(K_{R} \neq 1\right)$ cases are given in Table $\mathbf{1}$.

Comparison of flow regimes in slots whose permeability is not uniform is not straightforward. First, the critical Rayleigh numbers, $\mathrm{Ra}_{\mathrm{C}}$, above which convection develops in the fracture, are different; i.e. $\mathrm{Ra}_{\mathrm{C}}=1240$ and 3600 for 
the uniform and non-uniform permeability models, respectively (Tournier et al., 2000). The factor of three between these two Ra numbers is puzzling. The Rayleigh number of the stimulated domain, i.e. the domain characterized by a height of $H / 3$ and a conductive temperature difference across it of $\Delta \mathrm{T}_{\mathrm{R}}=$ $\Delta \mathrm{T} / 3$, is $\mathrm{Ra} / 9$. A factor of nine is therefore expected between the $\mathrm{Ra}_{\mathrm{C}}$ of the confined and unconfined layer (i.e. with an height equal to $\mathrm{H}$ and a conductive temperature difference across it of $\Delta \mathrm{T}$ ). In fact, the simulations show that the strength of convection and, hence, the $\mathrm{Ra}_{\mathrm{C}}$, increases with the dimensionless thickness of the fractured slot $\mathrm{a} / H_{\mathrm{R}}$ (which is three times greater than $\mathrm{a} / H$ ). This explains why $\mathrm{Ra}_{\mathrm{C}}$ drops by a factor of 3 instead of 9. Finally, the Rayleigh number that characterizes the convective regime in the higher permeability reservoir (i.e. the stimulated zone of the slot) can be defined by:

$$
R a_{\text {Reservoir }}=R a \times \frac{H_{R}}{H} \times \frac{\Delta T_{R}}{\Delta T} \times \frac{a / H}{a / H_{R}}
$$

As a result, the convective flow rate $Q_{\mathrm{F}}$ ' in the non-uniform permeability case (i.e. the confined simulation experiment) is nearly three times lower than that of the unconfined experiment (Fig. 12). The dimensionless critical injection rate $Q_{\mathrm{C}}$ ' also increases linearly with $\mathrm{Ra}$. In contrast to the uniform permeability case, $Q_{\mathrm{C}}$ ' drops by a factor of about 9 , i.e. three times more than that of $Q_{\mathrm{F}}$ ' (see Table 1 and Fig. 12), which suggests that the height of the stimulated domain $\left(H_{\mathrm{R}}\right)$ also interferes with the heat production process. Between the uniform and non-uniform permeability simulation experiments, the area of the heat exchange surface drops by a factor 3. Consequently, $Q_{\mathrm{F}}$, 
and $Q_{\mathrm{C}}$ ' are proportional to $\operatorname{Ra} \times H_{\mathrm{R}} / H$ and to $\operatorname{Ra} \times\left(H_{\mathrm{R}} / H\right)^{2}$, respectively. The experiments also show that below a dimensionless critical injection rate $Q_{\mathrm{C} 0}$, of about $2.7(6 \mathrm{~L} / \mathrm{s})$ the cold front has not reached the production well at $t^{\prime}=1.07 \times 10^{-4}(20$ years $)$. Thus, even when there is no free convection, cold water may be injected into the permeable slot without affecting the temperature of the produced fluid. This minimum injection rate within the higher permeability zone depends on the thickness of the stimulated domain and on the distance between the injection and production wells.

Finally, the relation between the maximal dimensionless injection rate $Q_{C}$, and dimensionless free convection rate $Q_{F}$, which is appropriate for the case of the Soultz-sous-Forêts stimulated reservoir, can be expressed as:

$Q_{C}{ }^{\prime}=2 \cdot Q_{F}{ }^{\prime}+4.9$

\subsection{Healing of the stimulated reservoir after 20 years of heat extraction}

Mineral dissolution and precipitation occur in high-temperature EGS systems. By monitoring the chemistry of the produced fluid during a single-well hydraulic test at Soultz-sous-Forêts, Pauwels (1997) detected changes in the physical properties of the stimulated reservoir that were attributed to mineral redistributions caused by waterrock interactions.

Colder water injected into a geothermal reservoir may react chemically with the hotter in-situ fluids and the reservoir rocks. As a result minerals may precipitate or dissolve and the permeability of the system may change. Using the KINDISP code of Madé et al. (1994), we calculated the fluid composition $\left(\mathrm{pH}, \mathrm{pCO}_{2}\right.$, mineral 
concentrations, and alkalinity) along a characteristic flow line connecting both wells. We used the temperature and flow fields calculated when $\mathrm{Ra}=16,200$, for a fluid injection rate $Q=40 \mathrm{~L} / \mathrm{s}$, and a stimulated reservoir of $750 \mathrm{~m} \times 750 \mathrm{~m} \times 35 \mathrm{~m}$; these parameters correspond to the model whose results are given in Fig. 11. The KINDISP program uses kinetic laws governing water-rock interactions and computes mineral precipitation and dissolution rates and related porosity changes along fluid flow lines.

Since the mineral assemblage in the system is dominated by carbonates, porosity increases around the injection well, and the flow line is progressively sealed as the injected fluid heats up during its flow towards the production well. If mineral precipitation took place exclusively at the entrance of the fractures instead of all along the crack walls, the reservoir permeability would likely drop dramatically around the production well, but this situation is unlikely to occur. Our simulation results show that the time required to seal the porosity of the fractured network is very long, and far greater than the expected economic lifetime of an EGS project. As a result, we are confident that the performance of EGS system at Soultz will not be significantly affected by the rock-fluid chemical interactions. Moreover, Jacquot (2000) showed that when the fracture network becomes partially sealed, acidification or hydraulic stimulation of the wells could restore the permeability in the fracture system.

\section{Summary, discussion and conclusions.}

Our models examine forced circulation into a vertical fractured slot bound between conductive walls. The heat extracted from an enhanced geothermal system over long periods of time will depend on the interaction between forced and free convective flows. Numerical experiments using different injection rates and Rayleigh numbers showed that the effects of injecting colder fluid into the fractured system depend on 
the strength of free convection. At high injection rates and low Rayleigh numbers, the cold fluid propagates radially away from the injection well, quickly reaches the production zone and inevitably leads to a dramatic drop in fluid production temperature. At low injection rates and high Ra numbers, the cold injectate is dragged downward towards the bottom of the reservoir by convection. Thus, the production zone is isolated from the colder fluid and the temperature of the extracted fluid remains high. For each $\mathrm{Ra}$, the dimensionless critical injection rate, $Q_{\mathrm{C}}$, which represents the transition between the two behaviors just described, is greater than six times the dimensionless convective flow rate $Q_{\mathrm{F}}$ '. More precisely, our modelling results lead to the following fit:

$Q_{\mathrm{C}}{ }^{\prime}=1.8 \times 10^{-3} \mathrm{Ra}+0.2$

The simulations also show that the dimensionless free convective flow rate $Q_{\mathrm{F}}$, grows linearly with $\mathrm{Ra}$ as long as the convective regime remains quasi-steady (Fig. 12). If a chaotic convective regime develops either by raising the $\mathrm{Ra}$ or by increasing the slot thickness a, $Q_{\mathrm{F}}$ ' does not remain proportional to the Rayleigh number. A specific study should be done to estimate the critical injection rate in EGS reservoirs subjected to chaotic thermal convection. However, in the particular case of the stimulated geothermal reservoir at Soultz-sous-Forêts, this regime is unlikely.

A variable permeability field was introduced to study the effect of a peripheral low-permeability zone on reservoir performance. It accounts for a highly stimulated zone around the injection and production points. The results of the simulations suggest that both convective and forced flows are confined to the highly permeable region of the slot. The injected fluid is deflected towards 
the production zone when it reaches the boundaries of the lower permeability region. Moreover, as the ratio between the permeability of the stimulated zone and that of the peripheral domain approaches 100 , the dimensionless free convection flow rate, $Q_{\mathrm{F}}$, and critical injection rate, $Q_{\mathrm{C}}$, seem to decrease as $H_{\mathrm{R}} / H$ and $\left(H_{\mathrm{R}} / H\right)^{2}$, respectively. For a permeability ratio $K_{R}=100$, a value reasonable for the Soultz-sous-Forêts site, our modelling results lead to the following fit:

$Q_{\mathrm{C}}{ }^{\prime}=2 \times 10^{-4} \mathrm{Ra}+4$.

Note that Eqs. (22) and (23) limit the $Q_{\mathrm{C}}$ ' variation range, when $\mathrm{K}_{\mathrm{R}}$ is between 1 and 100 (Fig. 12). The simulation conducted assuming no convection highlights the existence of a dimensionless critical injection rate, $Q_{\mathrm{C} 0}$, below which the cold front never reaches the production zone. Therefore, whatever the convective regime, there is a minimum injection rate below which short-circuiting is avoided for $t^{\prime} \leq 1.25 \times 10^{-4}$ (20 years), which corresponds to the expected period of production of the geothermal system at Soultz.

Our results compare favorably to the data from the Soultz September 1993 stimulation experiment. The injection started at low flow rates (less than $1 \mathrm{~L} / \mathrm{s}$ ) and was progressively increased to $40 \mathrm{~L} / \mathrm{s}$ after 15 days. Cornet (2000) shows the change in the depth of the observed microseismic events with time. The data indicate that a significant part of the injectate flowed along the lower half of the reservoir as long as the injection rate was less than $12 \mathrm{~L} / \mathrm{s}$. This value is very close to the critical injection rate we defined for a reservoir height of $750 \mathrm{~m}$ and $\mathrm{a} \mathrm{Ra}=4050$.

At higher injection rates, the seismic cloud extended both upwards and downwards. Such a behavior is consistent with the computed radial propagation of the cold front 
when we used an injection rate greater than $Q_{\mathrm{C}}$. This clearly highlights the role of convection in modifying the flow path of the injected fluid. Note that, during the hydraulic tests, the effective permeability increased as injection proceeded. Hence, in this type of experiment, the critical injection rate $Q_{\mathrm{C}}$ also increased with time.

We demonstrated that, for a given borehole spacing and a production lifetime of 20 years, short-circuiting of the injected fluid between the wells occurs at a critical injection rate of $6 \mathrm{~L} / \mathrm{s}$ if no convection develops within the stimulated reservoir $(\mathrm{Ra}=$ 0). Considering the optimal permeability for the stimulated reservoir (i.e. $\mathrm{Ra}>$ $16,200), Q_{\mathrm{C}}$ is equal to $61 \mathrm{~L} / \mathrm{s}$ if the total height of the stimulated reservoir is $2250 \mathrm{~m}$, but equal to $17 \mathrm{~L} / \mathrm{s}$ if the reservoir height $H_{\mathrm{R}}$ is only $750 \mathrm{~m}$ (see Table 1 and Fig. 12). At Soultz the injection rate is restricted to $20 \mathrm{~L} / \mathrm{s}$ to prevent the development of induced seismic events of magnitude greater than 3 . This rate is very close to the optimal fluid production rate for the stimulated geothermal reservoir of Soultz-sousForêts (see Fig. 12 and table 1).

Based on the thermodynamic properties of the fluid and the configuration of the stimulated reservoir, we can expect Rayleigh numbers ranging from 4050 to a maximum of 18,225 at Soultz-sous-Forêts. Our simulations using $\mathrm{Ra}=4050$ and $Q=$ $20 \mathrm{~L} / \mathrm{s}$ resulted in a thermal power of $5.7 \mathrm{MW}$ and a production temperature of $146.5^{\circ} \mathrm{C}$, after 20 years. Using a Rayleigh number of 18,225 , for which $Q$ is close to $Q_{\mathrm{C}}$, the produced thermal power is $8 \mathrm{MW}$ and the production temperature is $172^{\circ} \mathrm{C}$ (Table 1). It should be emphasized that the efficiency of heat conversion to electricity is so poor for a fluid production temperature lower than $150^{\circ} \mathrm{C}$ that a geothermal site could become of questionable economic feasibility.

A rough estimate of the heat production from an EGS system when the injection rate is supercritical can be obtained from calculations of the rock volume affected by 
the circulation. The maximum geothermal heat flux measured at Soultz is about 180 $\mathrm{mW} / \mathrm{m}^{2}$ (Gérard et al, 1984). Considering that all this heat is conducted through the $750 \mathrm{~m} \times 35 \mathrm{~m}$ bottom of the stimulated domain of the permeable granitic slot (see Fig 1), the maximum total steady heat recharge rate by conduction through this lower surface is about $4725 \mathrm{~W}$. This quantity is negligible compared to the amount of heat expected to be extracted during exploitation of the geothermal system (several MW). It is thus impossible to assume a steady reservoir temperature.

To estimate the cooling of the stimulated region of the permeable slot (i.e. the reservoir), we must consider the volume of rock affected by the fluid flowing between the injection and production wells. This volume is a function of the characteristic thickness of the region cooled inside the slot walls (i.e. $4 \sqrt{\kappa \cdot t}$ ) and the path used by the injected fluid in the reservoir. According to the strength of the convection, the flow of the fluid affects different domains inside the stimulated reservoir. When $\mathrm{Ra}=$ 18,225 , the height of the domain extends along the entire axis of the stimulated reservoir, i.e. it covers a vertical area of $750 \mathrm{~m} \times 750 \mathrm{~m}$; when $\mathrm{Ra}=4050$ this surface is reduced to $750 \mathrm{~m} \times 400 \mathrm{~m}$. The calculated temperature drop using an initial temperature of $169^{\circ} \mathrm{C}$ is about $27^{\circ}$ and $17^{\circ} \mathrm{C}$ for $\mathrm{Ra}=4050$ and 18,225 , respectively. These values confirm that this type of approximation is valid only when using supercritical injection rates. This is consistent with the fact that the production temperature under subcritical conditions is supplied by the hot convective current generated along the bottom of the high-permeability slot.

A precise knowledge of reservoir parameters is fundamental to the evaluation of the vigor of the convective regime and to optimizing the long-term profitability of the EGS geothermal project. The useful parameters are height, permeability and the thickness-to-height aspect ratio $(\mathrm{a} / H)_{\mathrm{R}}$ of the activated domain, but these are difficult 
to assess, since the geometry of the strongly fractured porous slot is very complex and is characterized by a heterogeneous permeability distribution (one should remember that the fluid is channeled into the high permeability zones).

A major difficulty when modeling EGS systems is the lack of thermal equilibrium between the fluid and the rock in the stimulated reservoir. This does not seem to be the case at Soultz, but might be true in other EGS. Under such circumstances, the transport of heat and mass would have to be simulated using more sophisticated models (Quintard et al., 1997) than the ones utilized here.

Our numerical experiments were conducted using thickness-to-height aspect ratios that were based on the distribution of the microseismic events recorded during Soultzsous-Forêts stimulation tests. Both the strength of free convection (Murphy, 1979) and the critical injection rate depend greatly on the thickness of the stimulated reservoir. This thickness must be carefully constrained if we are to achieve a realistic estimate of the thermal yield of a given EGS project.

Using the KINDISP code of Madé et al. (1994), we simulated mineral dissolution/precipitation during 20 years of exploiting an EGS system. Our simulations indicate that even for time periods far longer than 20 years, mineral precipitation will not be fast enough to significantly affect the permeability of the EGS reservoir at Soultz-sous-Forêts.

\section{Acknowledgments}

The authors would like to thank André Gérard, Jason McKenna, Michael

O'Sullivan, and an anonymous reviewer for their helpful comments, as well as Stefano Bellani, Marcelo Lippmann, Marnell Dickson, and Mike Toplis for major 
editorial improvements. The calculations were performed using computers of the Centre National d'Etudes Spatiales, Toulouse, France. The Institut de Recherche por le Développment (IRD) is acknowledged for supporting A.B. during his stay at Nouméa. This project was financed by the European Union STREP Pilot Plant.

\section{References}

Abé, H., Duchane, D.V., Parker, R.H., Kuriyagawa, M., 1999. Present status and remaining problems of HDR/HWR system design. Geothermics 28, 573-590.

Barbier, E., 2002. Geothermal energy technology and current status: an overview. Renewable and Sustainable Energy Rev. 6, 3-65.

Baria, R., Baumgärtner, J., Gérard, A., Jung, R., Garnish, J., 1999. European HDR research programme at Soultz-sous-Forêts (France) 1987-1996. Geothermics 28, 655669.

Cornet, F.H., 2000. Comment on 'Large scale in situ permeability tensor of rocks from induced microseismicity'. Geophys. J. Int. 140, 465-469.

Fitzgerald, S.D., Pruess, K., van Rappard, D.M., 1996. Laboratory studies of injection into horizontal fractures. In: Proceedings 21th Workshop on Geothermal Reservoir Engineering, Stanford University, Stanford, CA, pp. 113-118.

Genter, A., Traineau, H., 1993. Fracture distribution from core analyses in the basement of the Rhine Graben. In: Proc. European Union of Geosciences, E.U.G. VII 4-8 April 1993, Strasbourg, France. Terra Nova Abstract 5, pp. 217-218.

Genter, A., Dezayes, C., Gentier, S., Ledesert, B., Saussé, J., 2002. Conceptual fracture model at Soultz based on geological data. Fourth Int. H.D.R. Forum in Strasbourg 1998, Draft papers, Geologishe Jahrbuch, Sonderhefte Hannover, Baria, Baumgärtner, Gérard, and Jung Editors, 418 pp, 92-102.

Genter, A., Traineau, H., Dezayes, C., Elsass, P., Ledesert, B., Meunier, A., Villemin, T., 1995. Fracture analysis and reservoir characterization of the granitic basement in the Hot Dry Rock Soultz project (France). Geotherm. Sci. Tech. 4, 189-214.

Gérard, A., Jung, R., Baumgärtner, J., Baria, R., Gandy, T., Tran-Viet, T., 1998. Essais de circulation de moyenne durée conduits à Soultz-sous-Forêts en 1997. In : 
Résultats et interprétation préliminaires et perspectives, internal report GEIE-Soultzsous-Forêts, pp 62.

Gérard, A, Menjoz, A., Schwoerer, P., 1984. L'anomalie thermique de Soultz-sousForêts. Géothermie Actualités 3, 35-42.

Hettcamp, T., Klee, G., Rummel, F., 2002. Stress regime and permeability at Soultz derived from laboratory and in-situ tests. Fourth Int. H.D.R. Forum in Strasbourg 1998, Draft papers, Geologishe Jahrbuch, Sonderhefte Hannover, Baria, Baumgärtner, Gérard, and Jung Editors, 418 pp, 165-172.

Hicks, T.W., Pines, R.J., Willis-Richards, J., Xu, S., Jupe, A.J., Rodrigues, N.E.V., 1996. A hydro-thermo-mechanical numerical model for HDR geothermal reservoir evaluation. Int. J. Rock Mech. Min. Sci. \& Geomech. Abstr. 33, 499-511.

Hu, W., Steen, H.P., 1996. Transition to chaotic natural convection in tall Hele-Shaw slots. Phys. Fluids 8, 1929-1937.

Jacquot, J., 2000. Modélisation thermodynamique et cinétique des réactions géochimiques entre fluides de bassin et socle cristallin: application au site expérimental du programme européen de recherche en géothermie profonde (Soultzsous-Forêts, Bas-Rhin, France). Phd thesis, Université Louis Pasteur de Strasbourg, France, 202 pp.

Jung, R., Tran-Viet, T., Reich, W., Orzol, J., Dorner, D., Zaske, J., Schanze, U., 1997. Long term circulation test 97JUL12, HDR Project Soultz-sous-Forêts. Field Report Bgr Hannover, 1997.

Kestin, J., Khalifa, H.E., Abe, Y., Grimes, C.E., Sookiazan, H., Wakehan, W.A., 1978. Effect of the pressure on the viscosity of aqueous $\mathrm{NaCl}$ solutions in the temperature range $20-150^{\circ} \mathrm{C}$. J. Chem. Eng. Data 23, 328-336.

Kohl, T., Evans, K.F., Hopkirk, R.J., Rybach, J., 1995. Coupled hydraulic, thermal and mechanical considerations for the simulation of Hot Dry Rock reservoirs. Geothermics 24, 345-359.

Kolditz, O., Clauser, C., 1998. Numerical simulation of flow and heat transfer in fractured crystalline rocks: application to the Hot Dry Rock site in Rosemanowes (U.K.). Geothermics 27, 1-23.

Madé, B., Clément, A., Fritz, B., 1994. Modelling mineral/solution interactions: the thermodynamic and kinetic code KINDISP. Computers and Geosciences, 20, 13471363.

Murphy, H.D., 1979. Convective instabilities in vertical fractures and faults. J. Geophys. Res. 84, 6121-6130.

Murphy, H.D., Tester, J.W., Grigsby, C.O., Potter, R.M., 1981. Energy extraction from fractured geothermal reservoirs in low-permeability crystalline rock. J. Geophys. Res. 103, 7145-7158. 
Ormond, A., Boulègue, J., Genthon, P., 1995. A thermo-convective interpretation of heat flow data around ODP Leg 116 in a distal part of the Bengal Basin. J. Geophys. Res. 100, 8083-8095.

O’Sullivan, M.J., Pruess, K., Lippmann, M.J., 2001. State of the art of geothermal reservoir simulation. Geothermics 30, 395-429.

Patankar, S.V., 1980. Numerical heat transfer and fluid flow. Series in computational methods in mechanics and thermal sciences. McGraw-Hill, New York, NY, USA, $197 \mathrm{pp}$.

Pauwels, H., Fouillac, C., Fouillac, A.M., 1993. Chemistry and isotopes of deep geothermal saline fluids in the upper Grabben : origin of compounds and water rock interaction, Geochim. Cosmochim. Acta 57, 243-255.

Pauwels, H., 1997. Geochemical results of a single-well hydraulic injection test in an experimental Hot Dry Rock geothermal reservoir, Soultz-sous-Forêts, Alsace, France. Applied Geochemistry 12, 661-673.

Pearson, C., 1981. The relationship between microseismicity and high fluid pressure during hydraulic experiments in low permeability granitic rocks, J. Geophys. Res., 86, B9, 7854-7864.

Plenefisch, T., and Bonjer, K.P., 1997. The stress field in the Rhine Graben area inferred from earthquake focal mechanism and estimation of frictional parameters, Tectonophysics, 275, 71-97.

Press, W.H., Teukolsky, S.A., Vetterling, W.T., Flannery, B.P., 1992. Numerical recipes in Fortran. The Art of Scientific Computing, 2nd ed., Cambridge University Press, New York, NY, USA, 818 pp.

Pribnow, D.F.C., Schellschmidt, R., 2000. Thermal tracking of upper crustal fluid flow in the Rhine Graben. Geophys. Res. Lett. 27, 1957-1961.

Quintard, M., Kaviany, M., Whitaker, S., 1997. Two-medium treatment of heat transfer in porous media: numerical results for effective properties. Advances in Water Resources 20, 77-94.

Rabinowicz M., Dandurand, J.L., Jakubowski, M., Schott, J., Cassan, J.P., 1985. Convection in a North Sea oil reservoir; inferences on diagenesis and hydrocarbon migration. Earth Planet. Sci. Lett. 74, 4, 387-404.

Rabinowicz, M., Sempéré, J.C., Genthon, P., 1999. Thermal convection in a vertical permeable slot: implications for hydrothermal circulation along mid-ocean ridges. J. Geophys. Res. 104, 29275-29292.

Shapiro, S.A., Audigane, P., Royer, J.J, 1999. Large scale in situ permeability tensor of rocks from induced microsismicity. Geophys. J. Int. 137, 207-213. 
Shapiro, S.A., Royer, J.J., Audigane, P., 2002. Characterization of the reservoir permeability using fluid-injection induced seismic emission. Fourth Int. H.D.R. Forum in Strasbourg 1998, Draft papers, Geologishe Jahrbuch, Sonderhefte Hannover, Baria, Baumgärtner, Gérard, and Jung Editors, 418 pp, 219-225.

Tournier, C., Genthon, P., Rabinowicz, M., 2000. The onset of natural convection in vertical fault planes: consequences for the thermal regime in crystalline basement and heat recovery experiments. Geophys. J. Int. 140, 500-508.

Yanenko, N.N., 1968. Méthode à pas fractionnaire: résolution des problèmes polydimensionnels de la physique mathématique. Librairie Armand Colin, Paris, France, 205 pp. 
Table 1. Dimensional free convection flow rate $Q_{\mathrm{F}}$ and critical injection rate $Q_{\mathrm{C}}$, dimensionless free convection flow rate $Q_{\mathrm{F}}{ }^{\prime}$ and critical injection rate $Q_{\mathrm{C}}{ }^{\prime}$ for numerical experiments using permeability ratios of $K_{R}=1$ and $K_{R}=100$, and Rayleigh numbers (Ra) ranging from 0 to 24,300 .

\begin{tabular}{|c|cc|cc|cc|cc|}
\hline & \multicolumn{4}{|c|}{$\begin{array}{c}\text { Uniform permeability case } \\
\left(\mathrm{K}_{\mathrm{R}}=1\right)\end{array}$} & \multicolumn{3}{c|}{$\begin{array}{c}\text { Non-Uniform permeability case } \\
\left(\mathrm{K}_{\mathrm{R}}=100\right)\end{array}$} \\
\hline $\mathrm{Ra}$ & $Q_{\mathrm{F}}^{\prime}$ & $Q_{\mathrm{F}}(\mathrm{L} / \mathrm{s})$ & $Q_{\mathrm{C}^{\prime}}$ & $Q_{\mathrm{C}}(\mathrm{L} / \mathrm{s})$ & $Q_{\mathrm{F}^{\prime}}$ & $Q_{\mathrm{F}}(\mathrm{L} / \mathrm{s})$ & $Q_{\mathrm{C}^{\prime}}$ & $Q_{\mathrm{C}}(\mathrm{L} / \mathrm{s})$ \\
\hline 0 & & & 2.7 & 6 & & & 2.2 & 5 \\
2025 & 0.27 & 0.6 & 4 & 9 & & & 3.3 & 7.5 \\
4050 & 0.95 & 2.1351 & 7.6 & 17 & 0.012 & 0.028 & 4.4 & 10 \\
6075 & 1.6 & 3.605 & 11.3 & 25.5 & 0.18 & 0.4 & 5.1 & 11.5 \\
8100 & 2.3 & 5.11 & 15.1 & 34 & 0.39 & 0.875 & 5.8 & 13 \\
12,150 & 3.4 & 7.595 & 21.8 & 49 & 0.87 & 1.95 & 6.7 & 15 \\
16,200 & 4.3 & 9.73 & 27.1 & 61 & 1.29 & 2.9 & 7.6 & 17 \\
18,225 & 4.7 & 10.5 & 29.3 & 66 & 1.5 & 3.4 & 8 & 18 \\
24,300 & 5.6 & 12.6 & 34.7 & 78 & 2.18 & 4.9 & 9.3 & 21 \\
\hline
\end{tabular}




\section{Figure captions}

Fig. 1. (a) Configuration of the test performed in 1997 at the Soultz-sous-Forêts EGS site. The two boreholes, GPK1 and GPK2, are separated by a horizontal distance of $450 \mathrm{~m}$ and define an alignment parallel to the direction of the major horizontal stress. The height $\left(H_{\mathrm{R}}\right)$ and length $\left(L_{\mathrm{R}}\right)$ of the stimulated reservoir (gray area) connecting both wells is $750 \mathrm{~m}$. The (cold) water injected into GPK1 picks up heat within the stimulated reservoir, is extracted in well GPK2, the (hot $\}$ produced fluid is cooled with water from the pond near GPK2 and piped back to GPK1 for a new circulation cycle. (b) Geometry of the modeled domain. Due to the symmetry of the system, only the half-space $(y \geq 0)$ is shown. The light gray area represents half of the modeled fractured slot with thickness $\mathrm{a} / 2=17.5 \mathrm{~m}$. The slot exchanges heat with the impermeable granitic rock located at $y>a / 2$. A total width of $A / 2=300 \mathrm{~m}$ of granite is modeled. For the uniform permeability cases, a conductive layer of height $h=200$ $\mathrm{m}$ is added at the base of the model (dotted area) to prevent the formation of an unrealistically thin thermal boundary layer (see text). In this case, the width, $L$ and height, $H$ are both equal to $2450 \mathrm{~m}$. In the non-uniform permeability cases, the stimulated reservoir (dark gray area) corresponds to a high permeability zone with a height $H_{\mathrm{R}}=750 \mathrm{~m}$ a width $L_{\mathrm{R}}=750 \mathrm{~m}$ and a half thickness equal to a/2 $=17.5 \mathrm{~m}$. Since in this case the bottom conductive layer is not considered, the height and length of the modeled zone are $H=L=2250 \mathrm{~m}$. The two arrows point toward the injection and production points (i.e. where the wells are open to the stimulated reservoir). 
Fig. 2. Results for the case of uniform permeability in the vertical fractured slot and $\mathrm{Ra}=0$ (i.e. no density changes with temperature). Distribution of dimensionless temperatures along the fracture axis $(\mathrm{y}=0),(\mathrm{a})$ at $\mathrm{t}^{\prime}=1.07 \times 10^{-5}(2$ years $)$; (b) at $\mathrm{t}=$ $2.66 \times 10^{-5}(5$ years $) ;(c)$ at $\mathrm{t}^{\prime}=5.35 \times 10^{-5}(10$ years $) ;$ and $(\mathrm{d})$ at $\mathrm{t}^{\prime}=1.07 \times 10^{-4}(20$ years); (e) 3-D dimensionless temperature field inside the walls of the slot (i.e. a/2 $<y$ $<\mathrm{A})$ : the 0.6 and 0.8 isotherms at $\mathrm{t}^{\prime}=1.07 \times 10^{-4}(20$ years $)$ are drawn. The coldest surface $(\theta=0.6)$ overlies the warmest one $(\theta=0.8)$. The vertical plane at the back corresponds to the border of the model $(y=A)$, while the plane at the front borders the permeable slot $(y=a / 2)$. The dimensionless temperature of the injected fluid is -0.8 $\left(80{ }^{\circ} \mathrm{C}\right)$, and the dimensionless injection rate is $17.8(40 \mathrm{~L} / \mathrm{s})$. The injected fluid flows radially away from the injection well and the cold front reaches the production point after 4 years; (f) fluid production temperature versus time,

Fig. 3. Same as Fig. 2, but with $\mathrm{Ra}=4050$. The behavior of the injected fluid is similar to that when $\mathrm{Ra}=0$. The temperature of the produced fluid decreases after 5 years.

Fig. 4. Same as Fig. 2, but with $\mathrm{Ra}=8100$. The cold front is advected downward while it spreads radially.

Fig. 5. Same as Fig. 2, but with $\mathrm{Ra}=16,200$. The injected fluid is advected downward as a cold tongue by free convection. The production zone is isolated from the colder injectate and the fluid production temperature increases uniformly. 
Fig. 6. Change in dimensionless fluid production temperature during a dimensionless time $\mathrm{t}^{\prime} \leq 1.07 \times 10^{-4}$ (20 years) for different injection rates $(Q)$ in a fractured slot of uniform permeability. Panels (a), (b) and (c) show the changes for $\mathrm{Ra}=4050,8100$, and 16,200, respectively. In Panels (a) and (b) when $Q$ is high, the production temperature decreases after a dimensionless time of about $2.1 \times 10^{-5}$ (4 years); when $Q$ is low, the temperature rises continuously. In panel (c), for high rates the decrease in production temperature may be delayed due do interaction with a local upwelling plume (see Fig. 5). The dimensionless critical injection rate $Q^{\prime}{ }_{\mathrm{C}}$ above which the recovery temperature tends to drop is $17 \mathrm{~L} / \mathrm{s}, 34 \mathrm{~L} / \mathrm{s}, 61 \mathrm{~L} / \mathrm{s}$ for $\mathrm{Ra}=4050$, 8100 and 16,200 , respectively.

Fig. 7. Change of produced thermal power versus time for a dimensionless injection rate of $17.8(40 \mathrm{~L} / \mathrm{s})$ and $\mathrm{Ra}=4050,8100$, and 16,200. After t' $=1.07 \times 10^{-4}$ (20 years), the thermal power is $20 \%$ higher for the $\mathrm{Ra}=16,200$ case than for the one with $\mathrm{Ra}=4050$.

Fig. 8. Results for cases having a higher permeability in the stimulated domain and Ra $=0$ (i.e. no density changes with temperature). Panels (a), (b), (c), (d) represent snapshots of the thermal fields along the fracture axis $(y=0)$ at $t^{\prime}=1.07 \times 10^{-4}(20$ years), for a permeability contrast between the stimulated domain and the fractured slot $K_{R}=5,10,50$, and 100, respectively. The white rectangle indicates the higher permeability central zone within the slot. The change in dimensionless production temperature versus time is presented in panel (e). The dimensionless temperature of the injected fluid is -0.8 , i.e. $80^{\circ} \mathrm{C}$, and the dimensionless injection rate is 17.8 (40 
L/s). The "confinement effect" (see text) focuses the injected fluid towards the production zone.

Fig. 9. Same as Fig. 8, but with $\mathrm{Ra}=4050$. The behavior of the injected fluid is similar to the case with $\mathrm{Ra}=0$. There is a stronger decrease in production temperature when the permeability contrast $\left(\mathrm{K}_{\mathrm{R}}\right)$ becomes larger; see panel (e).

Fig. 10. Same as Fig. 8, but with $\mathrm{Ra}=8100$.

Fig. 11. Same as Fig. 8, but with $\mathrm{Ra}=16,200$. The interaction of the circulating fluid with the zones of different permeability $\left(K_{R}\right)$ creates two upwelling currents, one located below the production zone. This results in a transient increase in production temperature. Later, when the colder injectate reaches the production zone, the temperature of the extracted fluid drops.

Fig. 12. Change of the dimensionless free convection flow rate $Q_{\mathrm{F}}$ ' (a) and the dimensionless critical injection rate $Q_{\mathrm{C}}$ ' (b) with $\mathrm{Ra}$ for the two reservoir configurations $\left(K_{R}=1\right.$ and $\left.K_{R}=100\right)$. The two dimensionless parameters increase linearly with $\mathrm{Ra}$ for the range of Rayleigh numbers expected at Soultz-sous-Forêts. The convective flow rate $Q_{\mathrm{F}}$ ' for the non-uniform permeability case $\left(\mathrm{K}_{\mathrm{R}}=100\right)$ is three times lower than that for the uniform permeability case $\left(K_{R}=1\right)$. The hatched area corresponds to the domain of variation of $Q_{\mathrm{C}}$ ' with the Rayleigh numbers expected at Soultz-sous-Forêts when $\mathrm{K}_{\mathrm{R}}$ varies between 1 and 100 . 
a)

b)
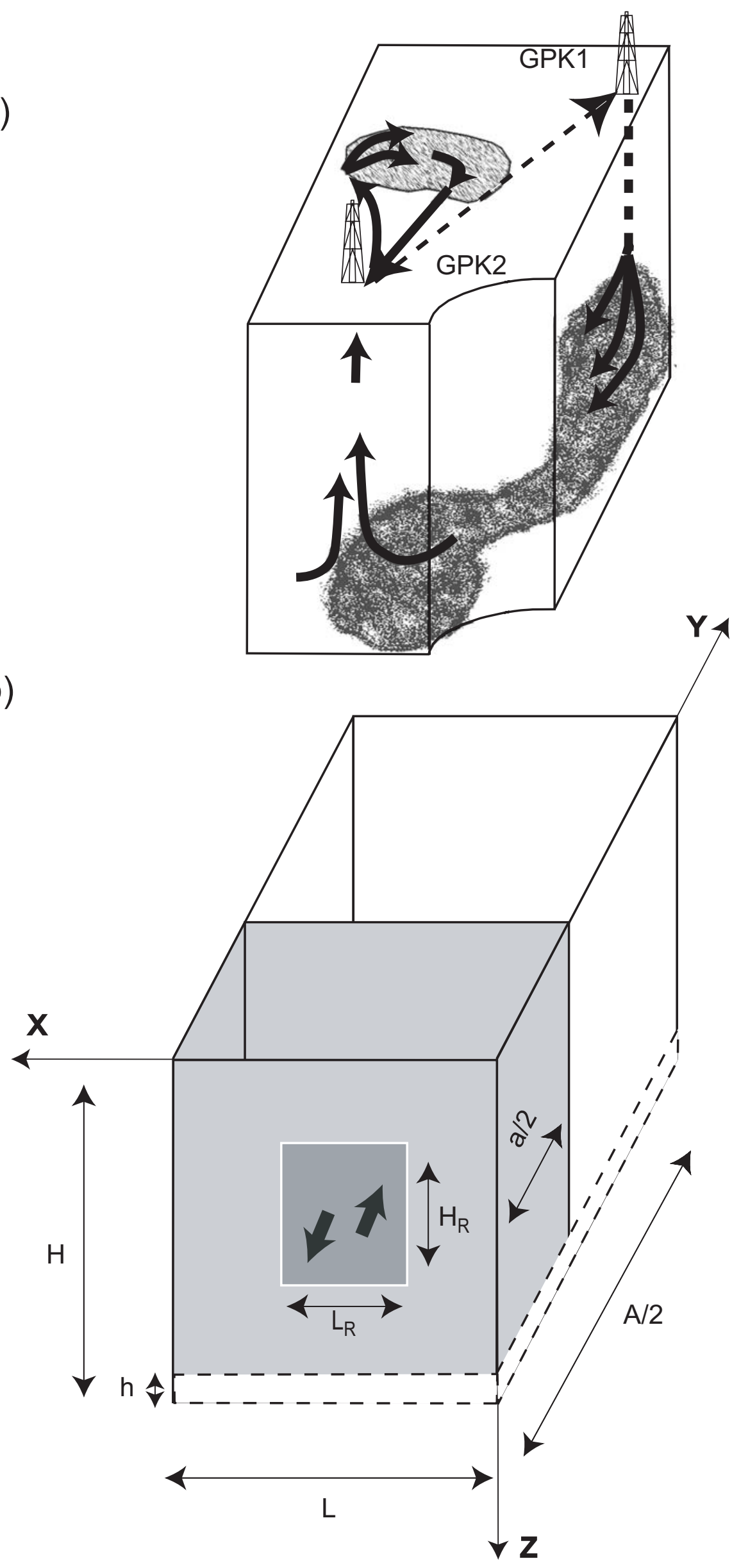

Figure 1 
a)

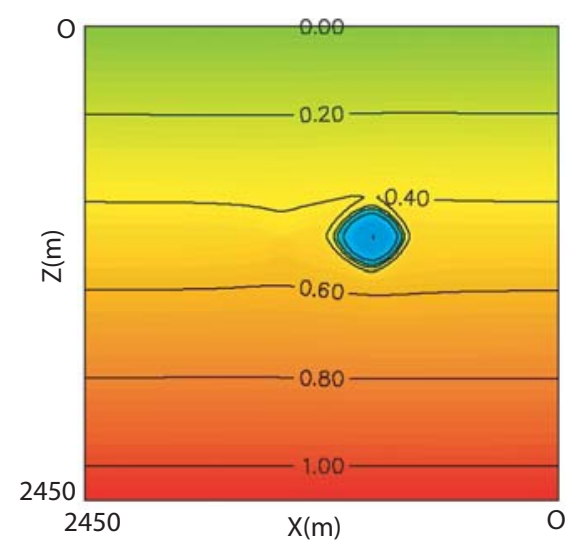

$-1$

c)

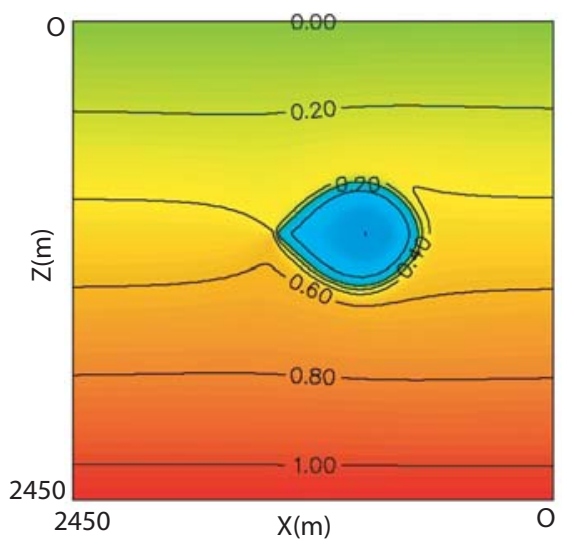

b )

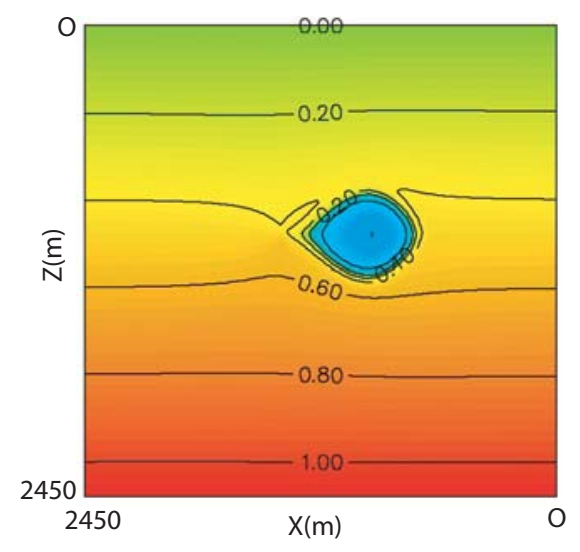

d)

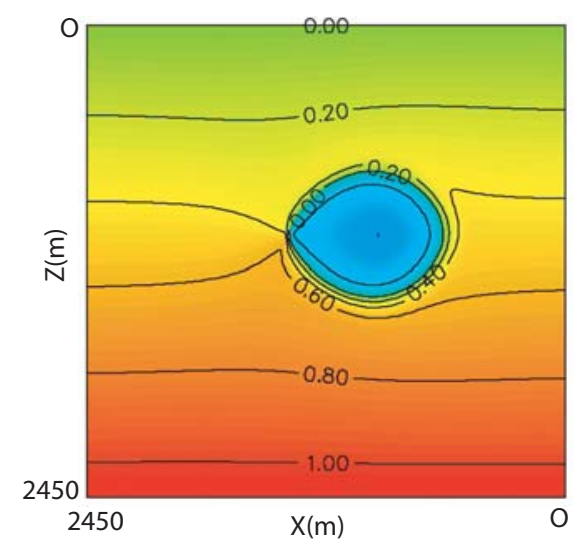

e )

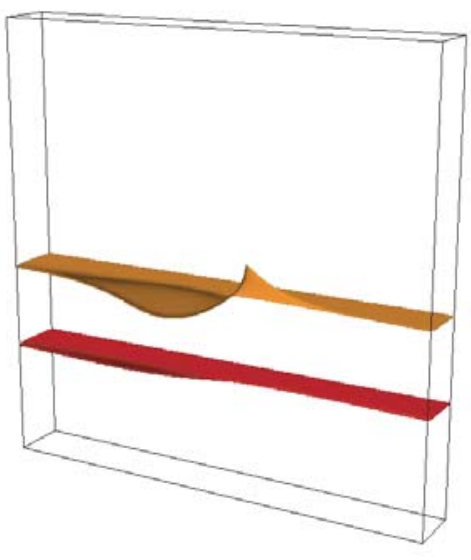

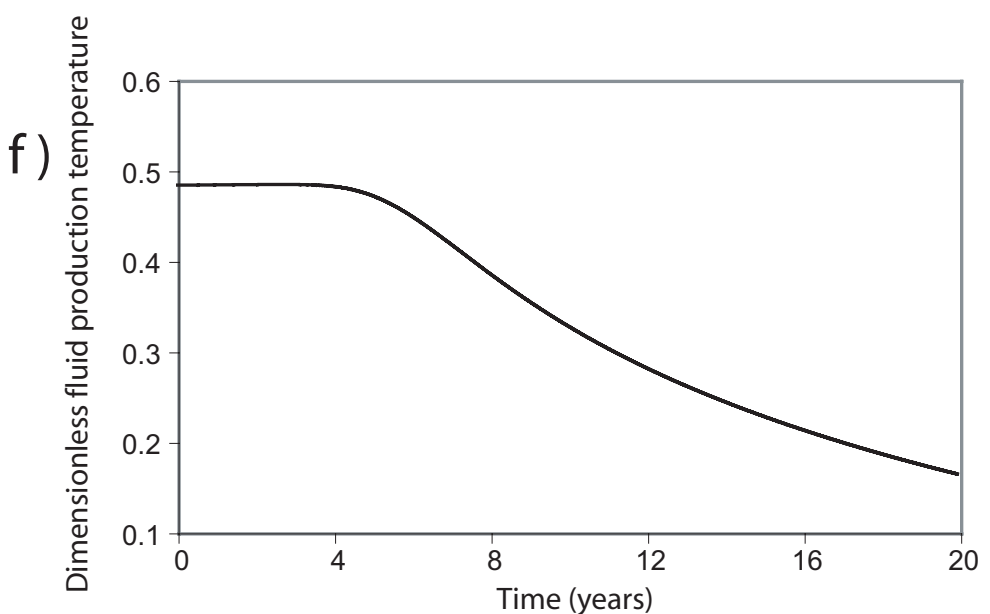

Figure 2 
a)

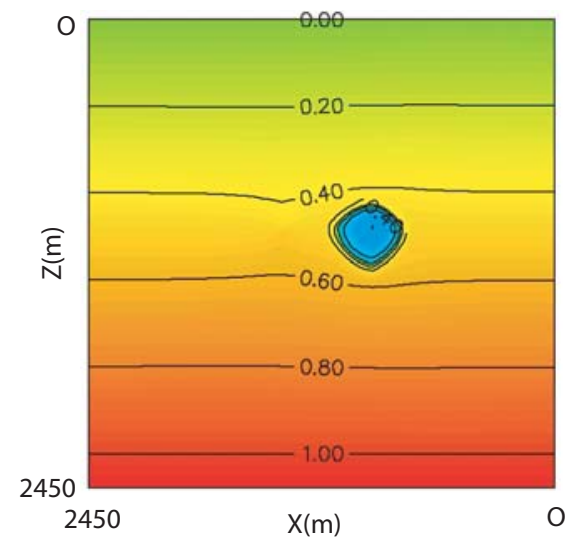

b)

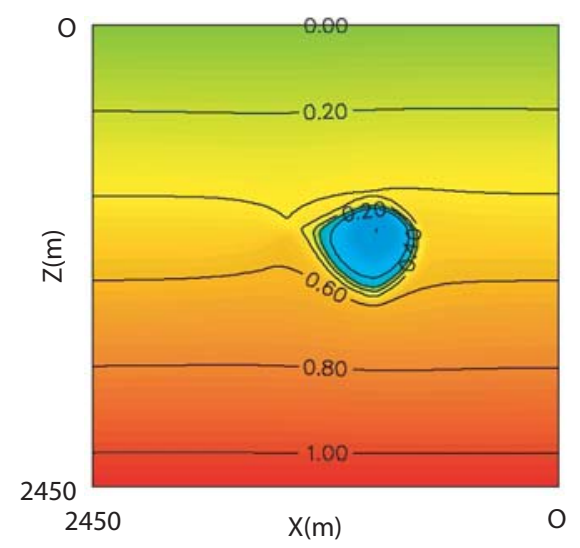

c)

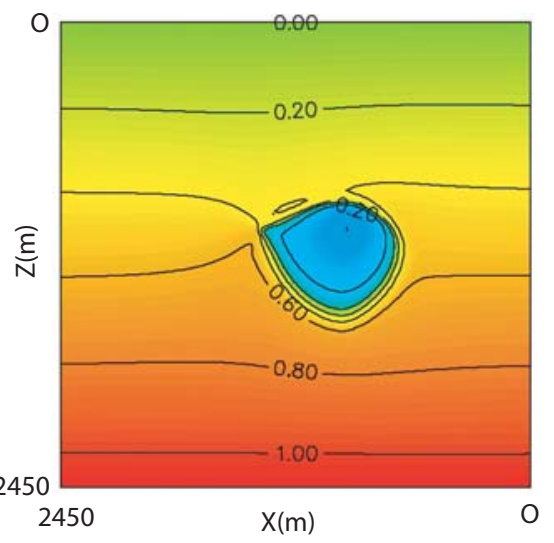

0

d)

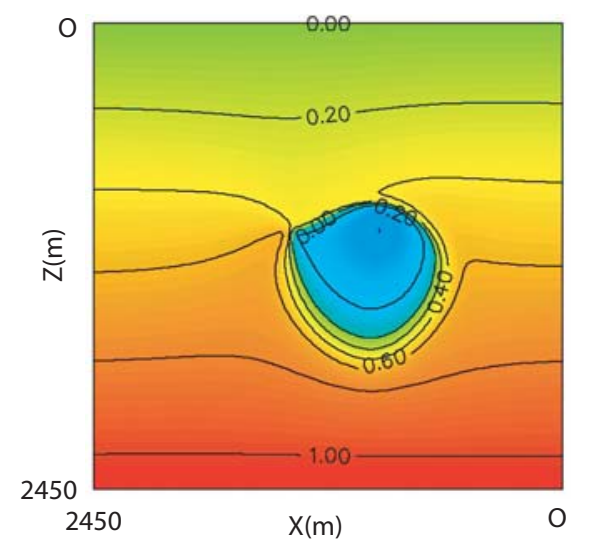

e)

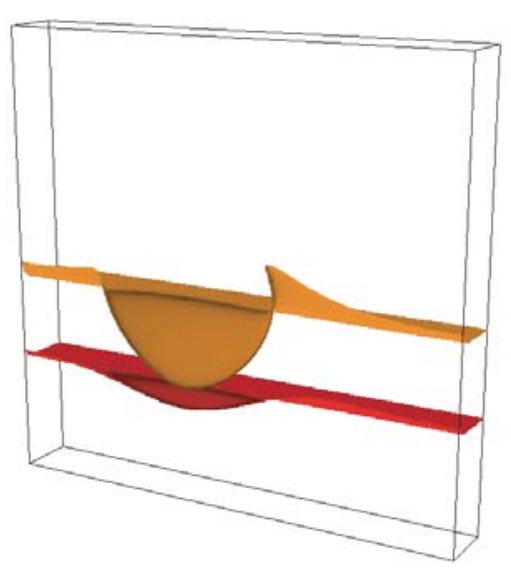

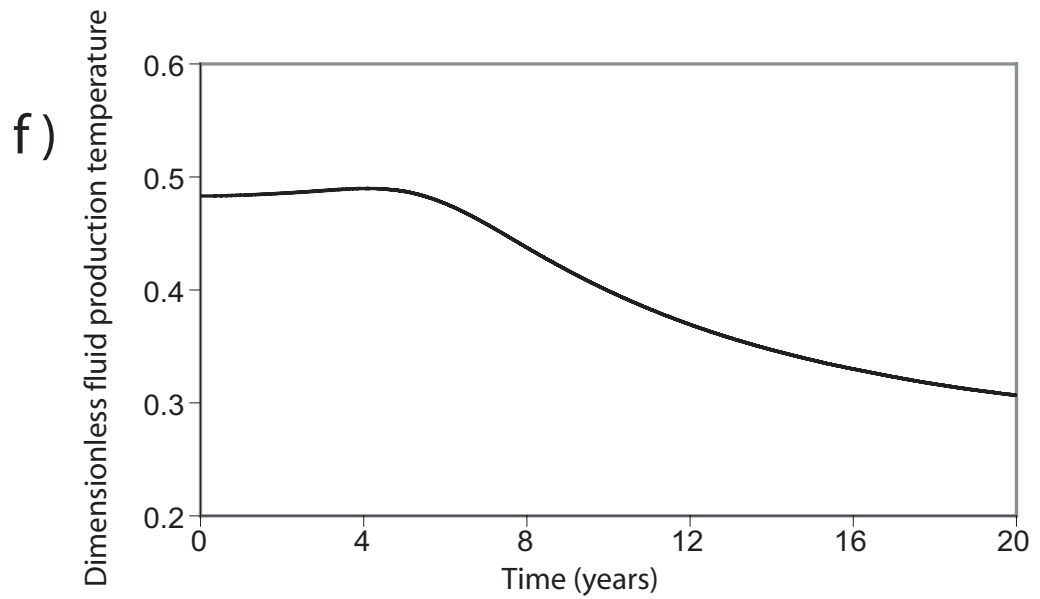

Figure 3 
a)

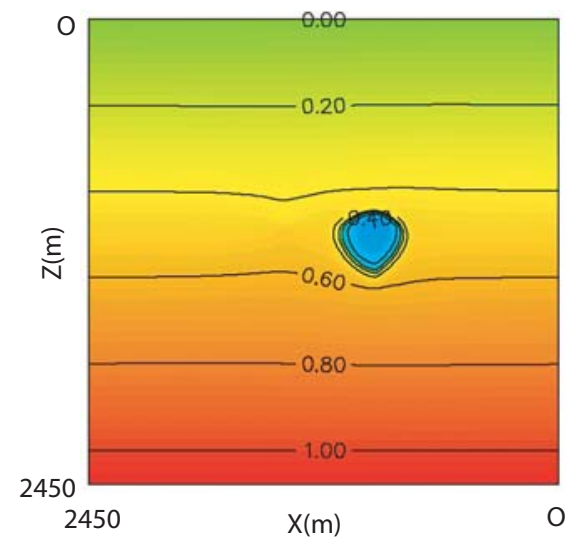

b)

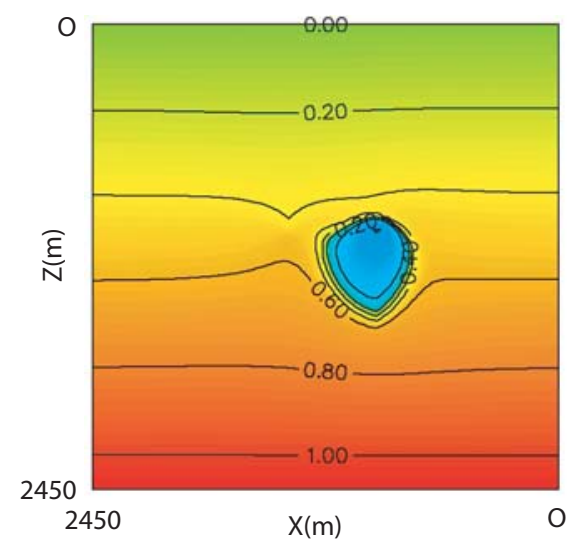

c)

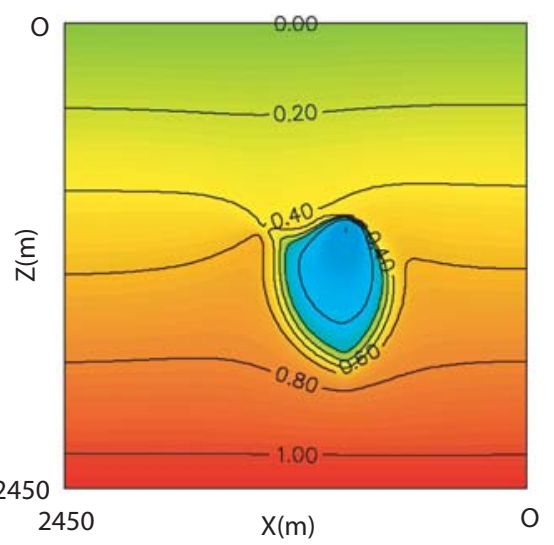

0

d)

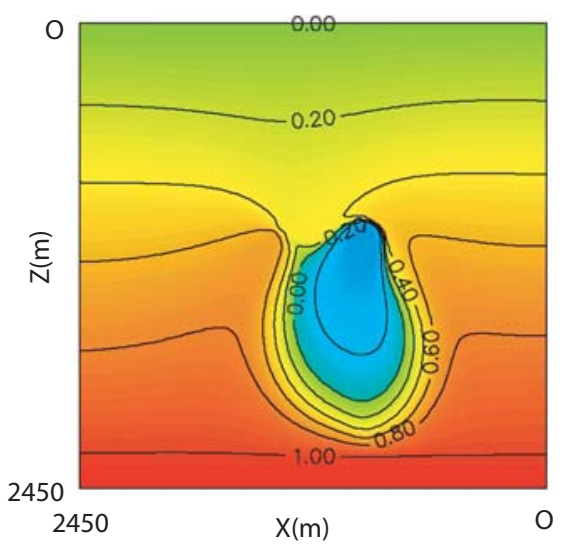

e )

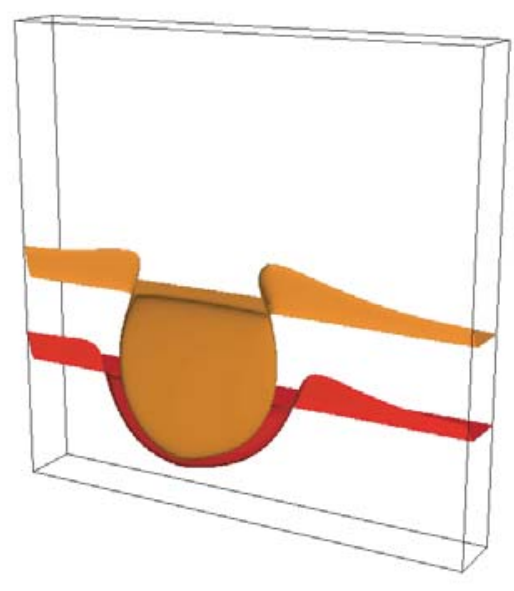

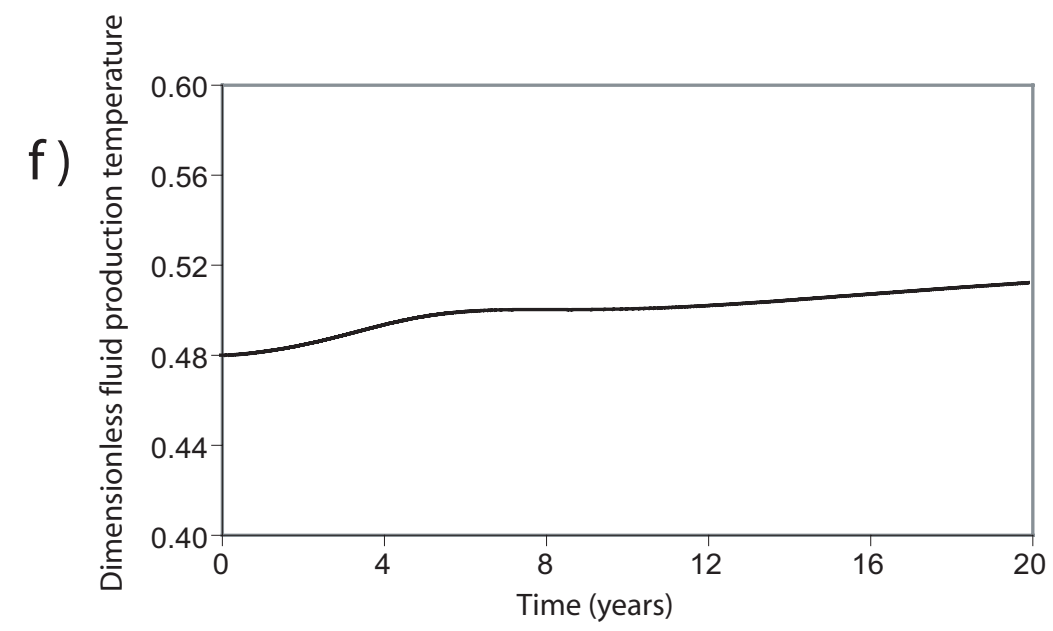

Figure 4 
a)
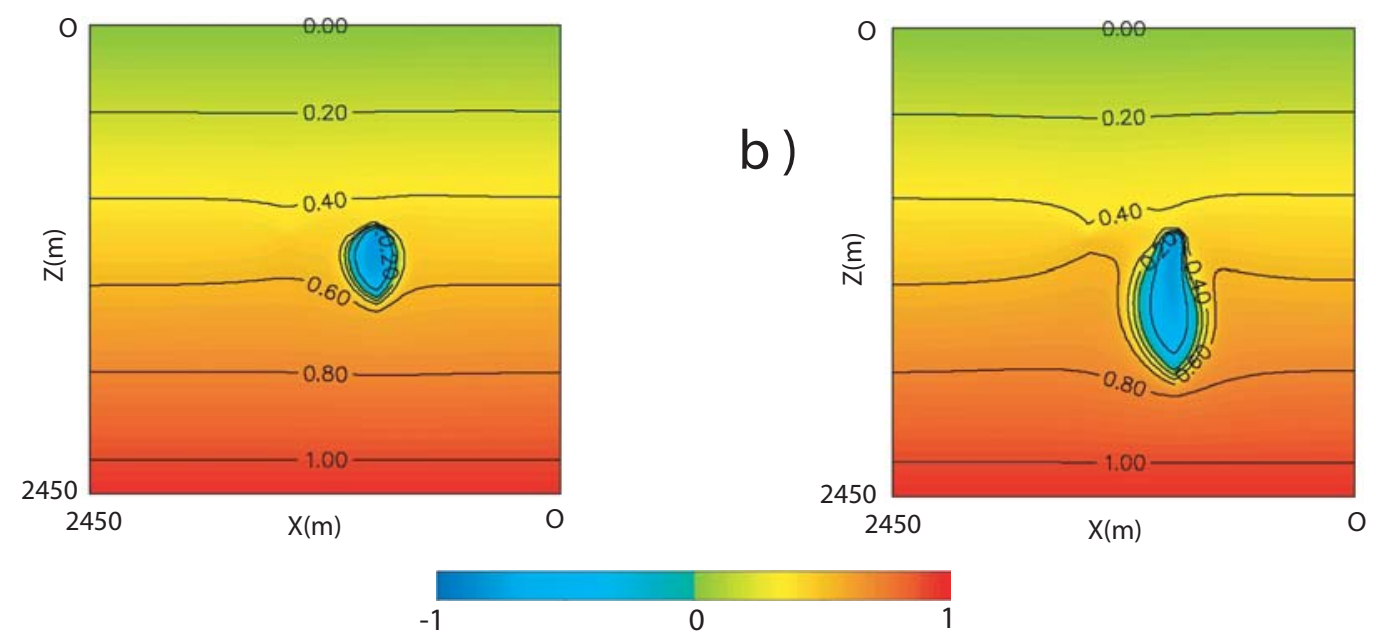

c)

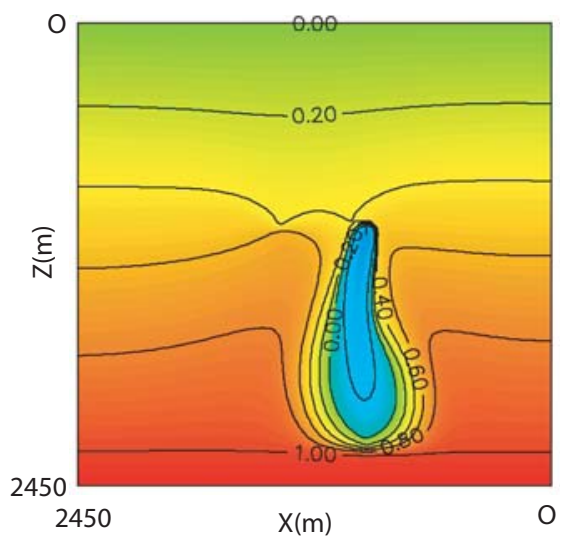

e)

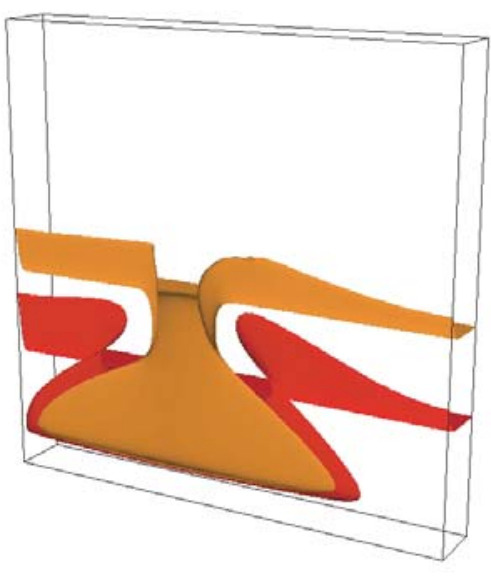

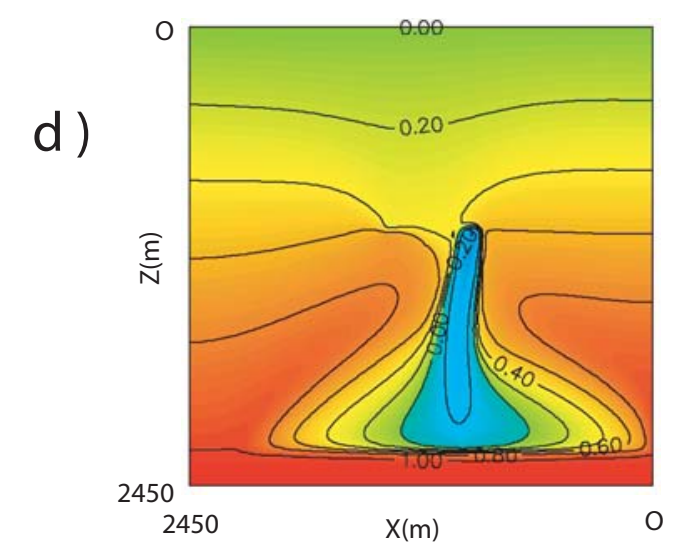

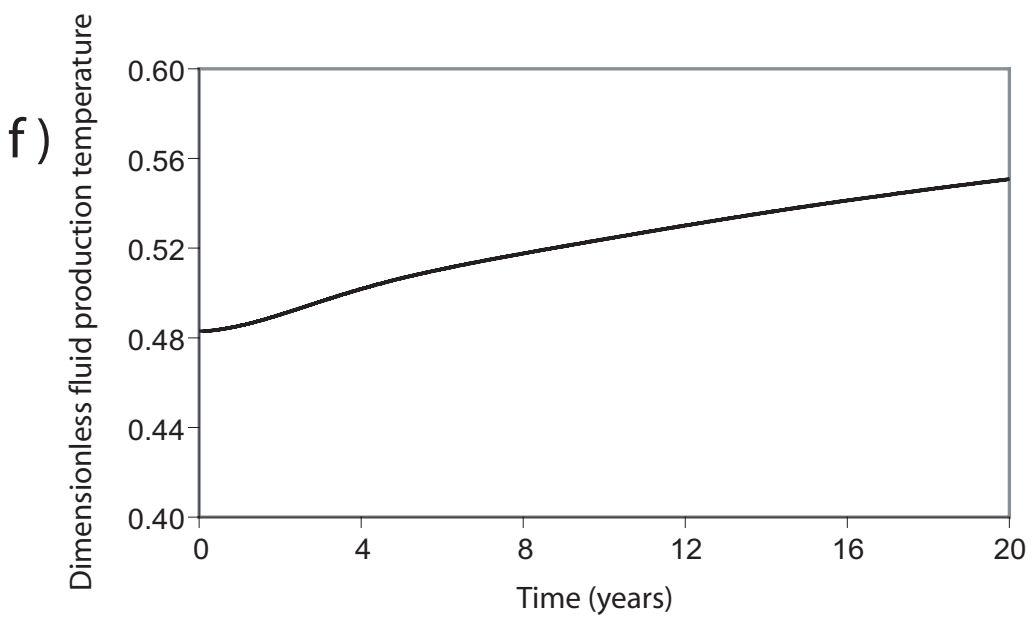

Figure 5 
a)

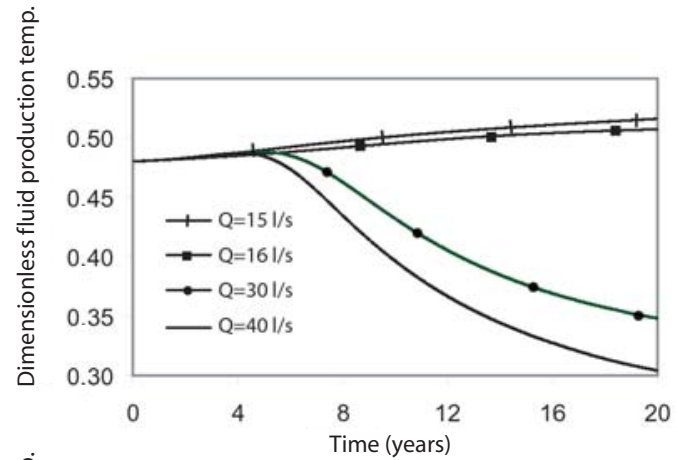

b)
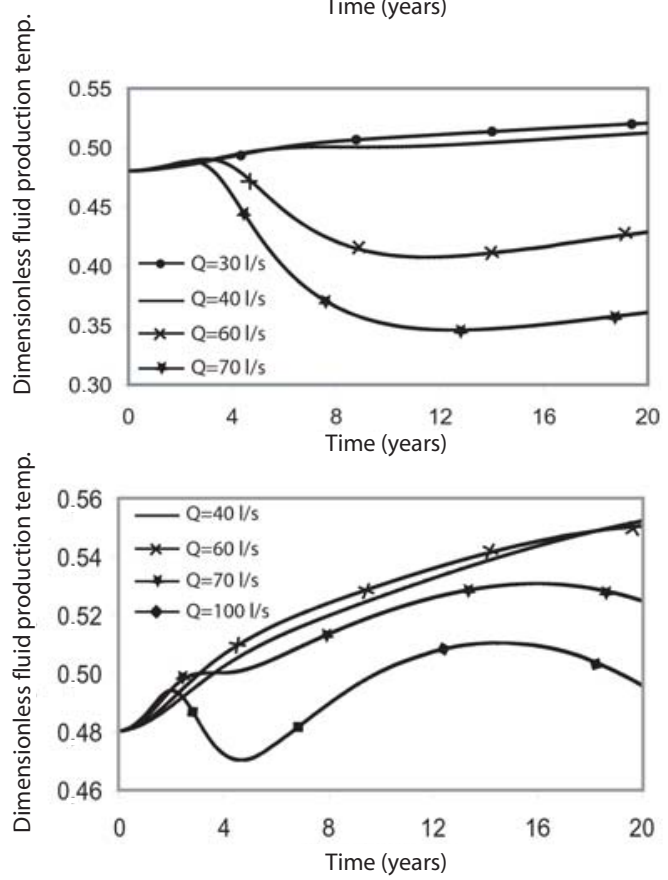

Figure 6 


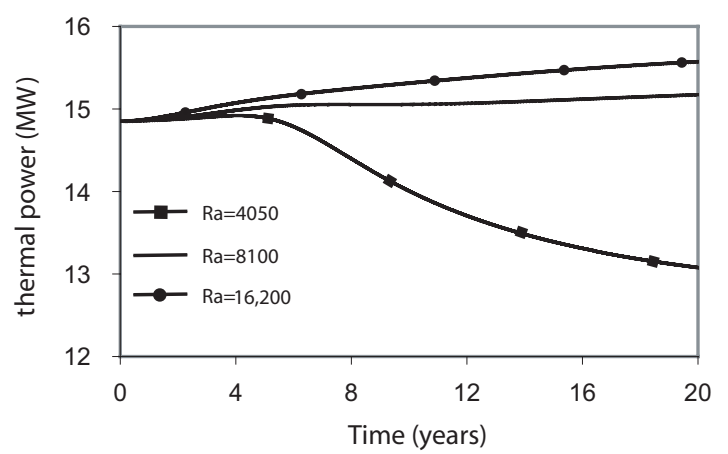

Figure 7 
a)

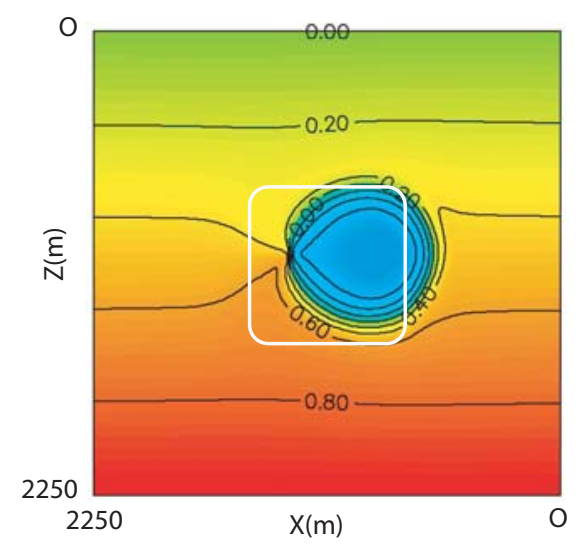

b)

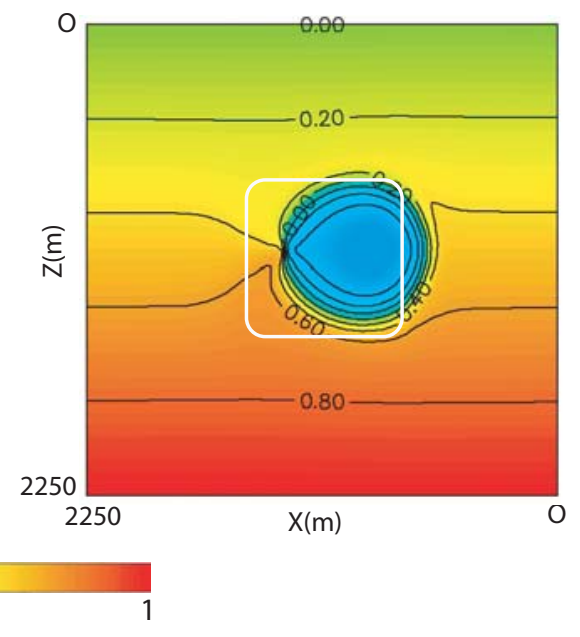

c)

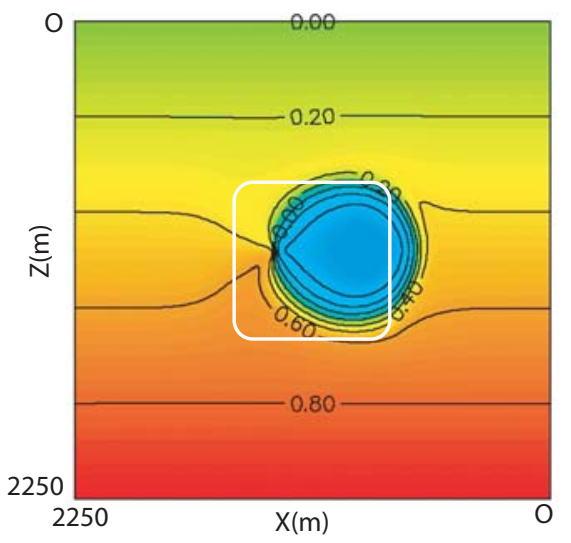

d)

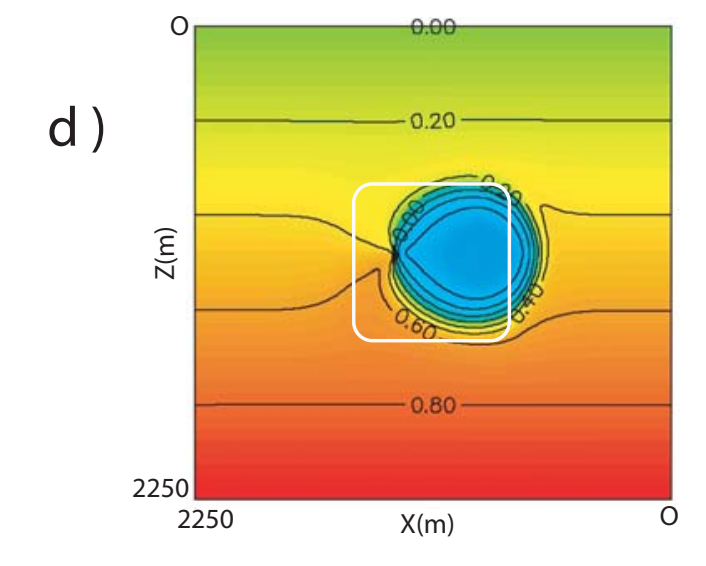

0

$\mathrm{Ra}=0$

e)

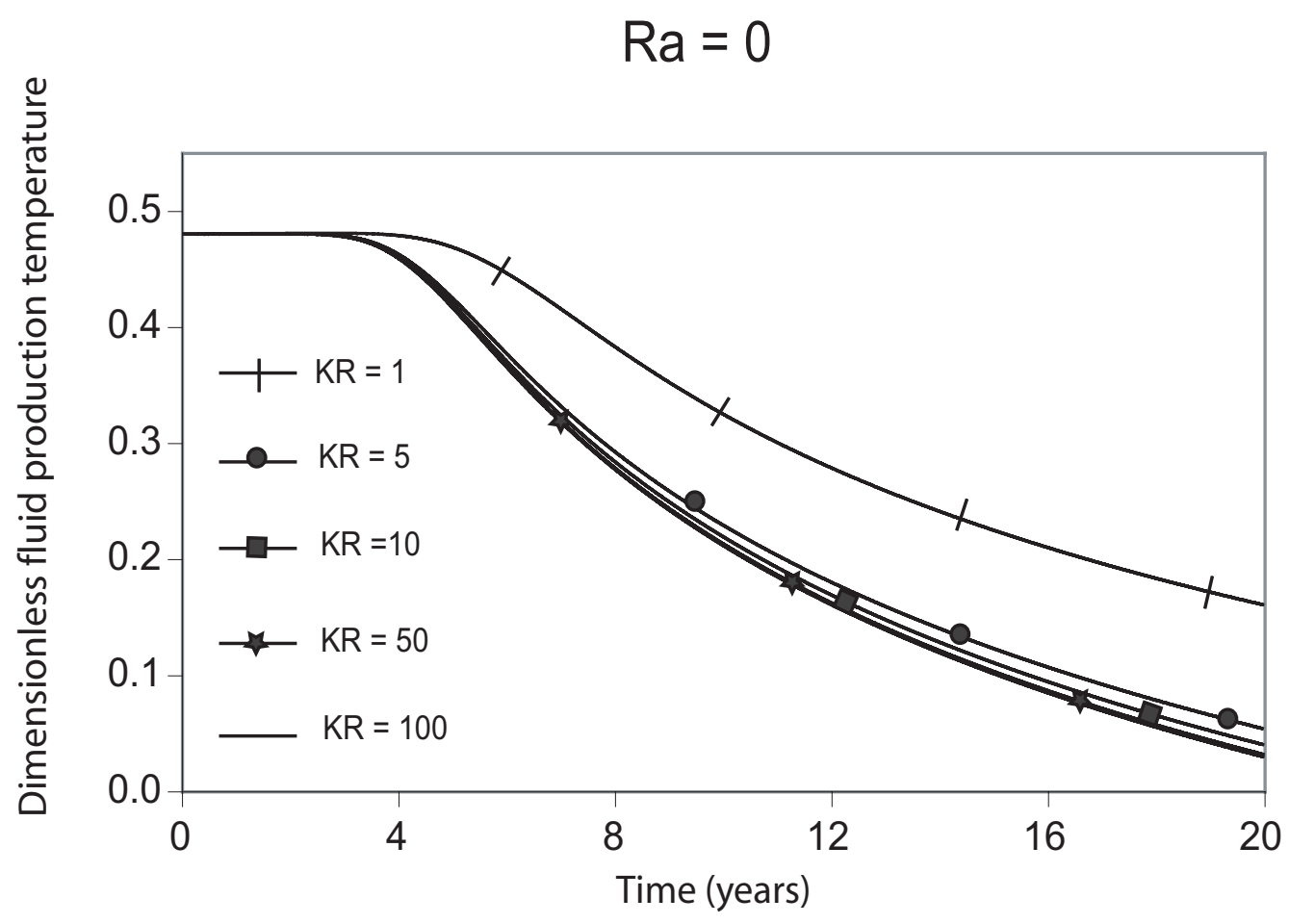

Figure 8 
a)

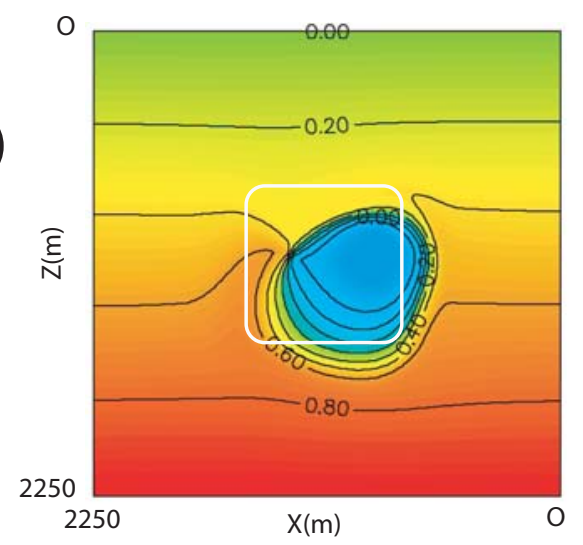

b)

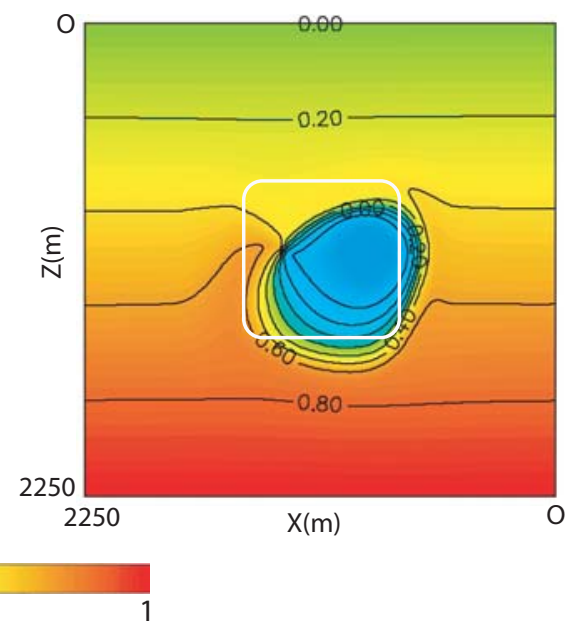

d)

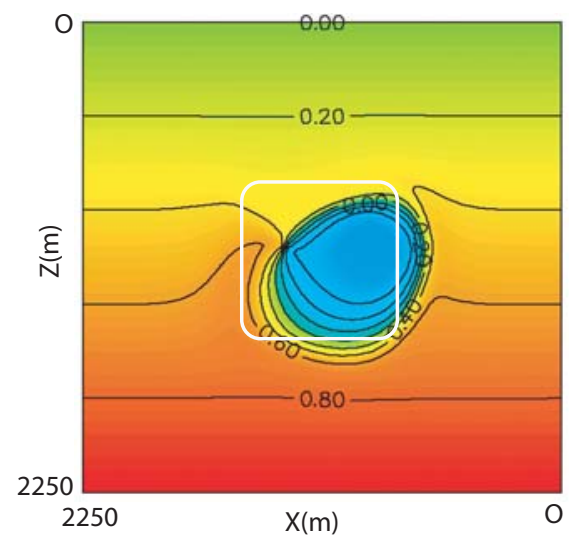

$\mathrm{Ra}=4050$

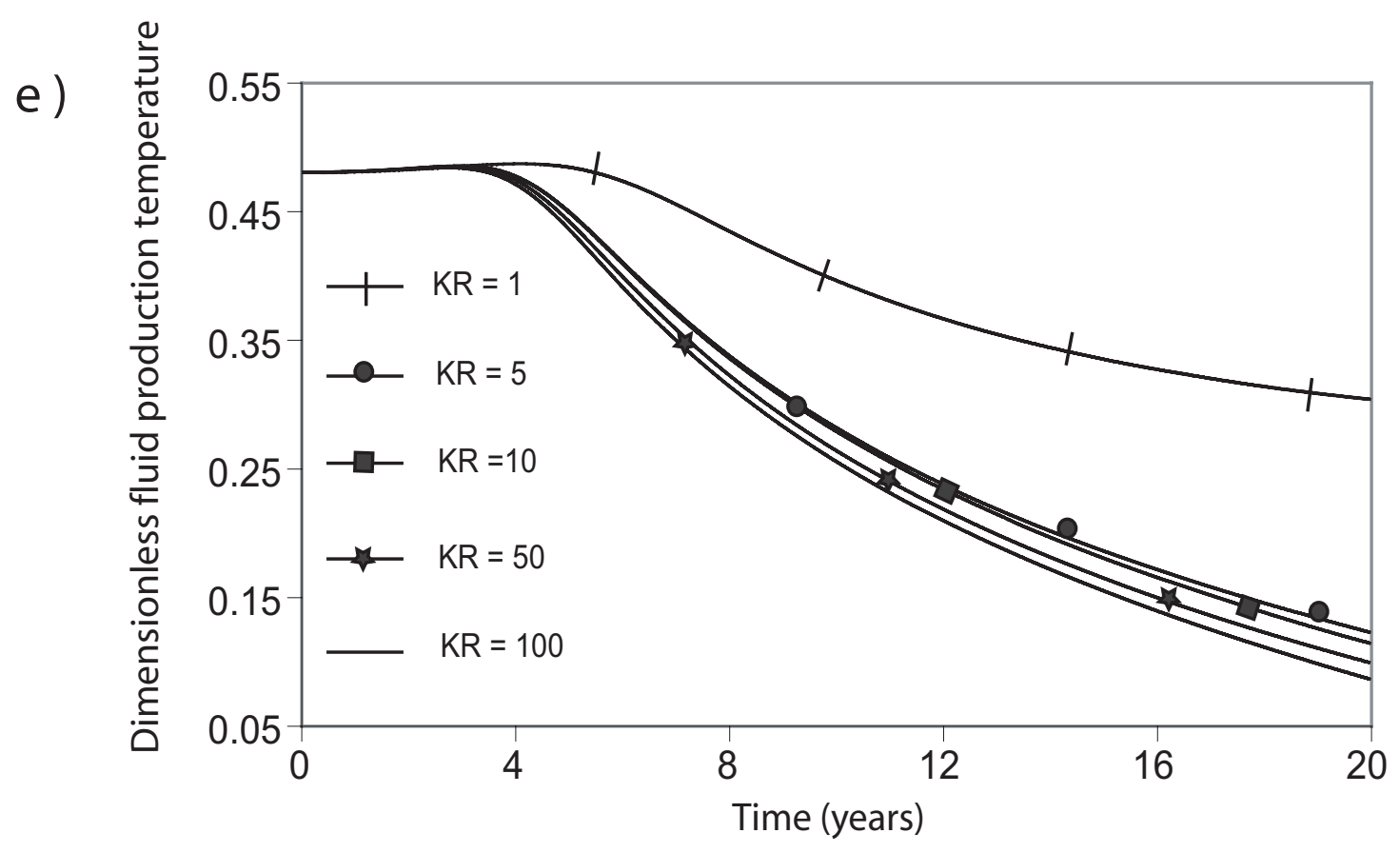

Figure 9 
a)

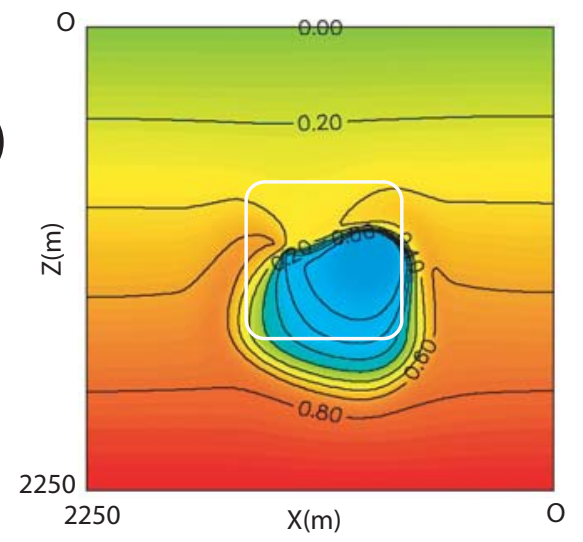

b)

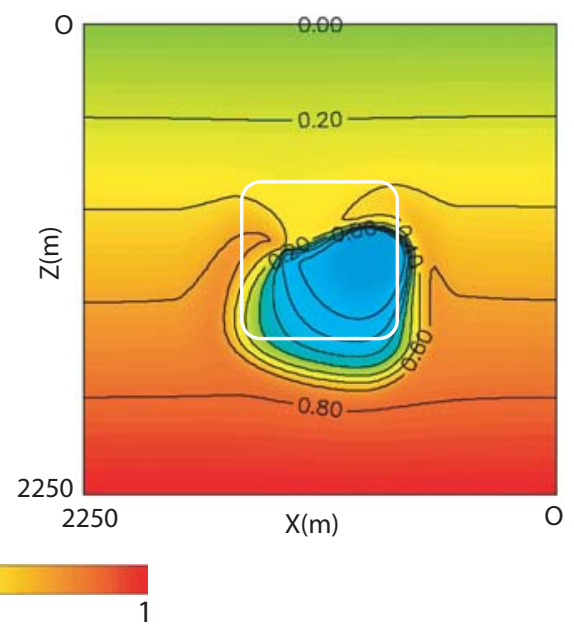

d)

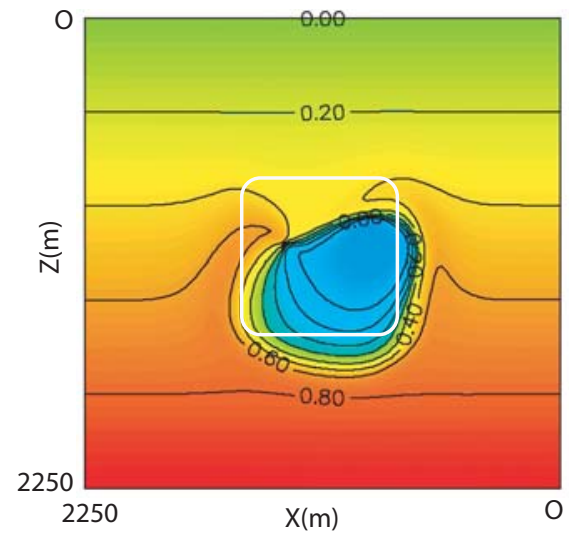

$\mathrm{Ra}=8100$

e)

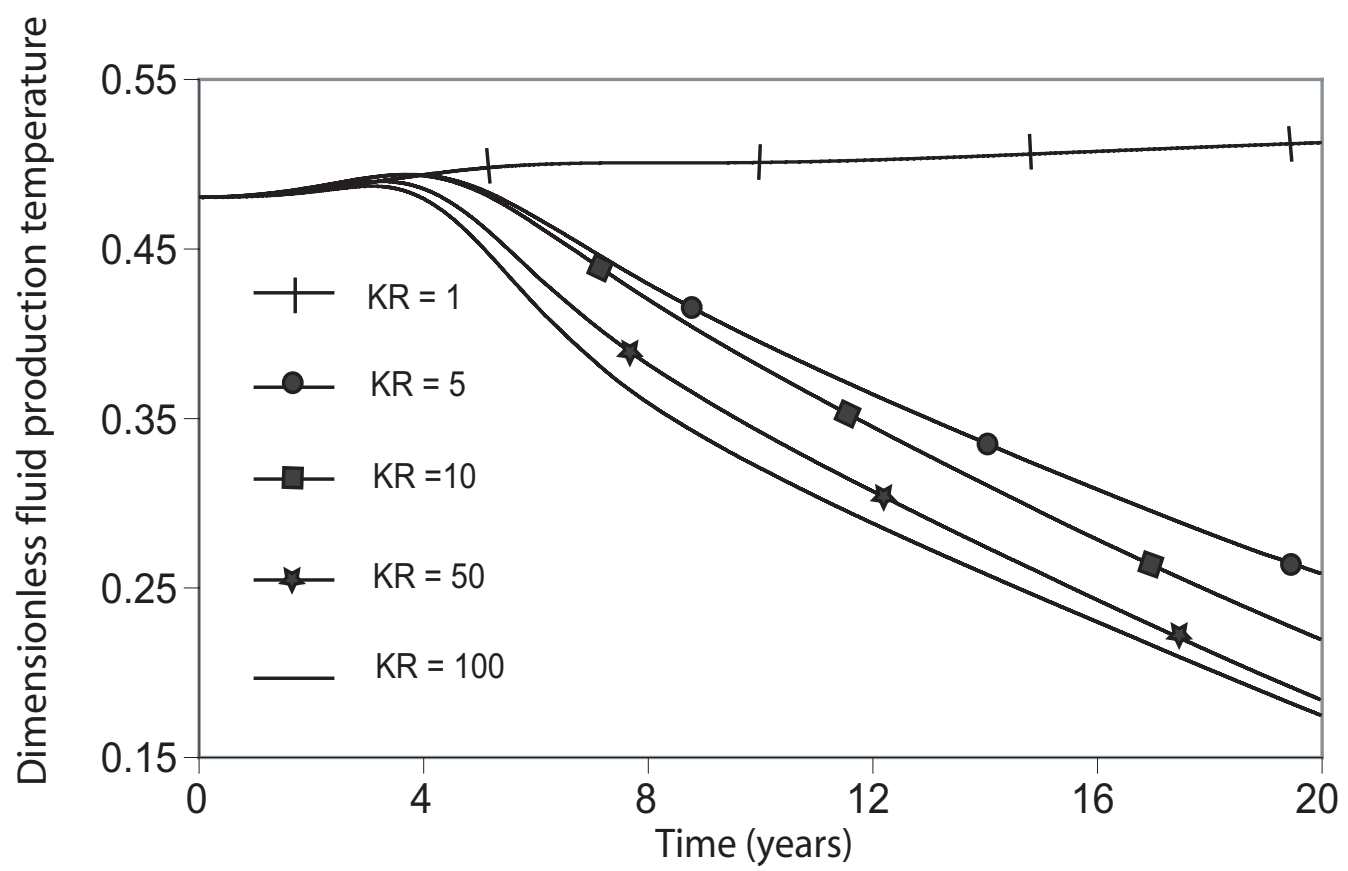

Figure 10 
a)

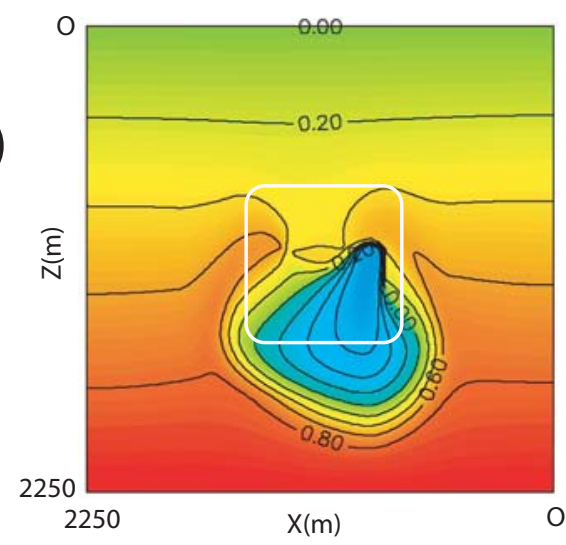

b)

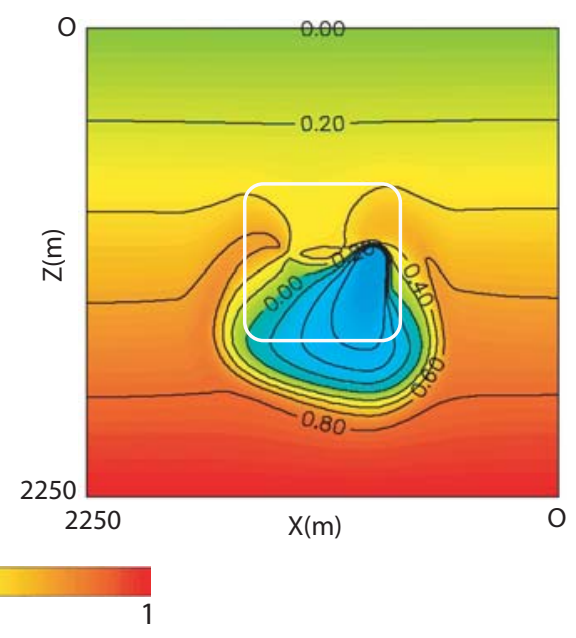

d)

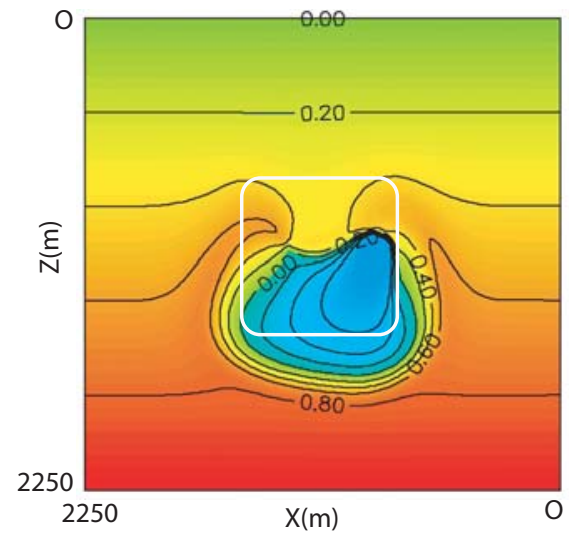

$\mathrm{Ra}=16,200$

e )

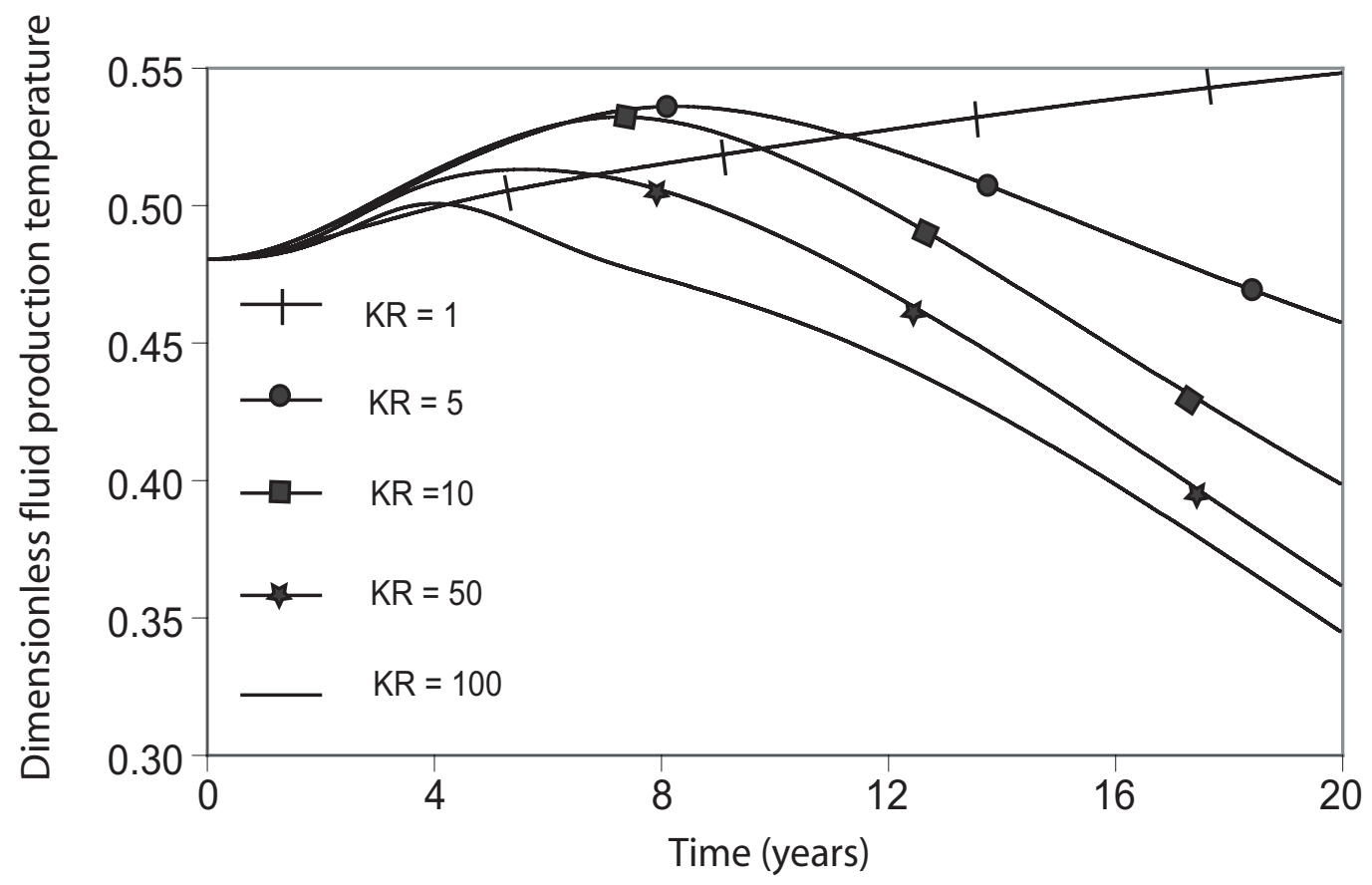

Figure 11 
(a)

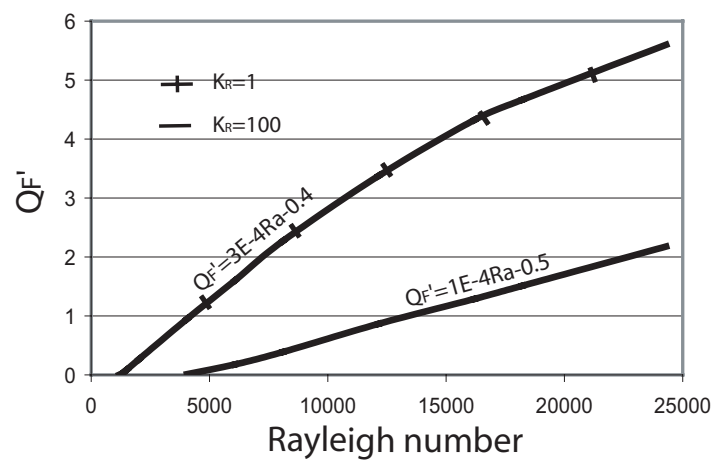

(b)

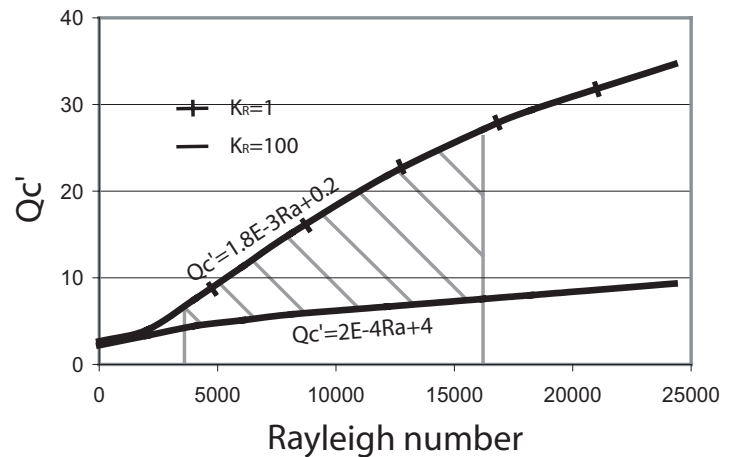

Figure 12 